\title{
ENTRE EL VERGEL Y LA PLATERÍA MAPUCHE: EL TRABAJO DE METALES EN LA ARAUCANÍA POSCONTACTO (1550-1850 D.C.)*
}

\author{
BETWEEN EL VERGEL AND THE MAPUCHE SILVERWORK: METAL- \\ WORKING IN POST-CONTACT ARAUCANIA (AD 1550-1850)
}

\author{
Roberto Campbell ${ }^{1}$
}

\begin{abstract}
Los 300 años que median entre 1550 y 1850 d.C. constituyen una gran incógnita respecto del devenir del trabajo de metales indígena en la Araucanía. Para abordar esto se definen dos tradiciones de trabajo de metales: la El Vergel y la Platería Mapuche. La primera corresponde a tiempos prehistóricos y es la existente hacia 1550 d.C., y la segunda alcanza su esplendor desde 1850 d.C. Los registros arqueológico (material) e histórico (escrito y gráfico) son usados para acceder al período entre estas dos fechas. Este a su vez fue evaluado siguiendo cuatro ejes: materias primas, piezas, individuos y contextos. Se plantea que ocurrió (a) un progresivo desplazamiento desde una tecnología mayormente basada en cobre a una casi exclusivamente en plata, y (b) un recambio completo de la morfología de las piezas manufacturadas. Sin embargo, las piezas metálicas continúan siendo usadas casi solo por mujeres. Por último, ocurre una tan alta valorización de la Platería Mapuche, que se imposibilita su incorporación en los contextos funerarios y se desvalorizan los adornos en cuentas. El devenir del trabajo de metales de tiempos históricos es así testimonio de los profundos cambios políticos, sociales y económicos que experimenta la sociedad indígena, desde la llegada europea hasta su incorporación al estado chileno.
\end{abstract}

Palabras claves: trabajo de metales, metalurgia, El Vergel, Platería Mapuche, complejidad social, contacto cultural.

\begin{abstract}
The indigenous Araucanian metalworking development from AD 1550 to AD 1850 remains unknown. In order to approach this period two metalworking traditions are defined: the El Vergel and the Mapuche Silverwork. The former corresponds to prehistoric times and was present to $A D 1550$ whereas the latter reached its splendour from AD 1850. Material archaeological records as well as graphic and written historical records are used to discuss the period between these two dates. This period was assessed following four axes: raw materials, artifacts, individuals, and contexts. It is proposed that there was: (a) a shift from a mostly copper-based technology to a technology based almost exclusively on silver, and (b) a complete replacement of the morphology of the manufactured artifacts. However, the metal artifacts continued to be worn almost exclusively by women. Finally, the Mapuche Silverwork reached such a high valuation that it precluded its incorporation into funerary contexts and also resulted in the devaluation of the beads adornments. The development of metalworking in historic times is then a testimony of the deep political, social, and economic changes that the indigenous society went through, from the European arrival until its incorporation into the Chilean state.

Key words: Metalworking, metallurgy, El Vergel, Mapuche Silverwork, social complexity, cultural contact.
\end{abstract}

En este trabajo abordaremos el devenir que tuvo el trabajo de metales en la Araucanía durante tiempos históricos, desde el arribo europeo en 1550 d.C. y hasta 1850 d.C., en la antesala del inicio de la "Pacificación de la Araucanía". La relevancia de tratar dicho tema radica precisamente en que la imagen que tenemos de este es aún de baja resolución y le faltan varias partes como para poder visualizarlo cabalmente. Desde la arqueología $-\mathrm{y}$ el registro arqueológico- la causa de esta situación se encuentra en las escasas investigaciones que se han abocado a los tiempos históricos o poscontacto (post-1550 d.C.) en el sur de Chile. A su vez, el registro histórico (escrito y gráfico) entrega una imagen parcial de este fenómeno. Por ello nuestra estrategia se funda en hacer uso de ambos registros, a fin de que estos sirvan para iluminar una situación que sería inadecuada de abordar en prescindencia del uno o del otro registro.

Por tanto, presentaremos dos grupos de datos. Por un lado, tendremos la información material que proveen los escasos sitios arqueológicos considerados como de tiempos históricos, y es a este conjunto al que haremos alusión cuando nos refiramos al "registro arqueológico". Por otro lado, estará la información tanto escrita como gráfica

\footnotetext{
* Artículo editado por Diego Salazar y Valentina Figueroa, en su calidad de editores invitados de la Revista.

1 Departamento de Antropología, Facultad de Ciencias Sociales, Universidad de Chile, Santiago, Chile. r.campbellt@gmail.com
} 
que entregan diversos documentos desde el siglo XVI al XIX, a la que trataremos como el "registro histórico". Lo anterior no implica, obviamente, desconocer la materialidad de los documentos ni el carácter histórico del registro arqueológico, sino que se funda en reconocer y segregar operativamente las dos vías de entrada al fenómeno bajo estudio.

Estos dos registros serán luego discutidos siguiendo cuatro ejes que captan bien la complejidad de este tema de investigación; estos ejes son: materias primas, piezas, individuos y contextos.

Finalmente, el objetivo es poner de manifiesto y subsanar una situación de parcial desconocimiento, como también contribuir desde el estudio del trabajo de metales, respecto de comprender los procesos de transformación social que ocurrieron en tiempos históricos (aunque sus antecedentes sean prehistóricos) en y a la sociedad indígena de la Araucanía.

\section{Conceptos, Aclaraciones y Limitaciones}

Con el fin de poder abordar el objeto de estudio se propone la existencia de dos tradiciones de trabajo de metales en la Araucanía: la "tradición de trabajo de metales El Vergel” y la "Platería Mapuche". Esto permitirá establecer dos puntos temporales fijos desde los cuales poder transitar por los 300 años que este trabajo trata. La primera de estas tradiciones tiene un origen prehistórico y era la que existía al año 1550 d.C. La segunda, al año 1850 d.C., está iniciando su época de mayor esplendor. De hecho, coherentemente con la perspectiva diacrónica que se adopta, la imagen que se plantea para el año 1550 d.C., y con anterioridad a esta fecha, estará basada exclusivamente en el registro arqueológico precontacto. Esto es así pues la información histórica, aun si proviene de los primeros años de la Conquista, está ya inscrita en un momento poscontacto. La adscripción prehistórica de las piezas metálicas está dada así por las fechas obtenidas y las asociaciones contextuales de las piezas.

La tradición de trabajo de metales El Vergel, enmarcada dentro del desarrollo del Complejo El Vergel (1000-1550 d.C. [Aldunate 1989, 2005; Bahamondes 2009; Campbell 2004, 2011; Dillehay 1990, 2007; Menghin 1959-60; Quiroz 2010]), está representada por los denominados "aros cuadrangulares con muesca", "aros circulares planos", "aros circulares simples", pulseras, anillos y pendientes (Campbell 2004) (Figura 1). Estas piezas se caracterizan por ser de tamaño pequeño, poco espesor, estar constituidas por una sola pieza, no presentar partes móviles ni articuladas entre sí y no contar con decoración grabada, en sobrerrelieve ni calados. Todas las piezas están manufacturadas en cobre, excepto los "aros circulares planos" que también lo están en plata. La naturaleza del cobre y la plata es metalúrgica (Campbell y Figueroa 2013; Campbell y Plaza 2015; cf. Campbell 2004, 2005, 2008).

La distribución de estas piezas está circunscrita a Isla Mocha, la costa y el valle central entre los ríos Biobío y Toltén (Figura 2). Los escasos contextos funerarios con restos humanos y presencia de piezas metálicas tienden a indicar su asociación con individuos adultos femeninos o subadultos -en los que no se puede determinar sexo- (Padre Las Casas [Urquieta 1978; Valdés 1978], P21-1 [Constantinescu 1997], Co-2 [Quiroz et al. 2005]). Por último, es necesario hacer mención también a la presencia de cuentas de piedra y concha (Padre Las Casas [Gordon 1978], La Candelaria [Bahamondes et al. 2006]), las que también fueron usadas como adornos y, como veremos más tarde, estarían muy ligadas al desarrollo de la Platería Mapuche.

La Platería Mapuche (Fontecilla 1946; Guevara 1929; Inostroza et al. 1986; Joseph 1928; Morris 1987; Painecura 2011; Reccius 1983; Schindler 1985) se caracteriza por la producción de piezas volumétricas, grandes, compuestas, con partes móviles y estar decoradas con grabados, sobrerrelieves o calados, manufacturadas mayormente en plata ${ }^{1}$. Esta descripción es importante pues un problema inmediato que surge al momento de abordar la "Platería Mapuche", es precisamente su definición. Ello pues dentro de las piezas emblemáticas de esta tradición se incluyen piezas (como aros cuadrangulares sin muesca) que bien pudieran remontarse a tiempos prehispánicos (aunque nosotros discrepamos con esto, como veremos más adelante), mientras que otras (como los sikil y trapelakucha ${ }^{3}$ ) parecen surgir recién después de 1860 (Figura 3). A esto hay que agregar el problema de referir retrospectivamente cualquier pieza de metal que aparezca en la Araucanía como "platería" (Inostroza y Sánchez 1986). Lo anterior, aun si dicha pieza proviene de contextos prehispánicos o simplemente no está manufacturada en plata (lo que incluso llega al extremo de referir toda pieza de metal como que estuviese hecha en plata).

Estos aspectos refuerzan entonces la intención de abordar diacrónicamente el dinámico proceso 

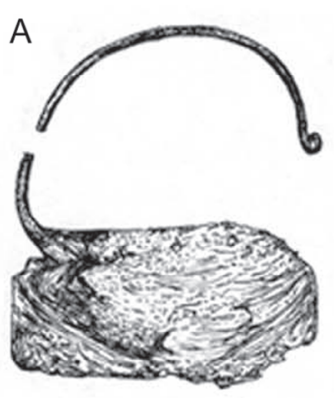

Co-2

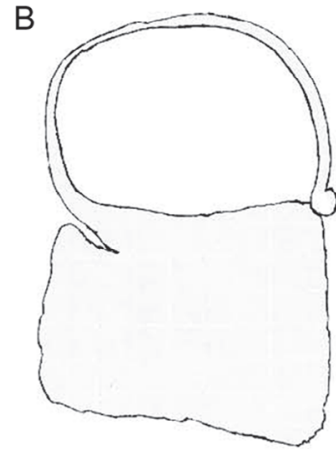

La Candelaria
C

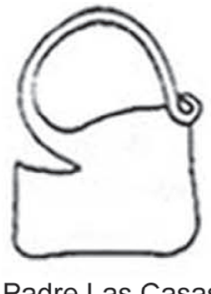

E

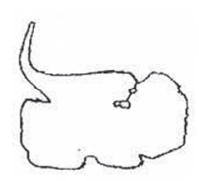

La Candelaria

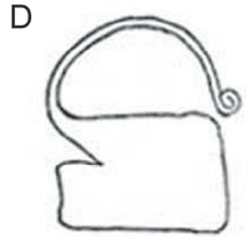

Fundo Carmona

(Angol)

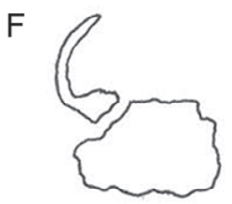

Ralipitra I

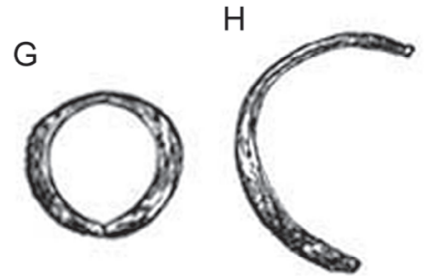

P21-1

(Isla Mocha)

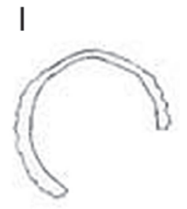

La Candelaria

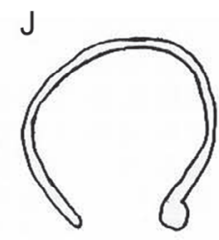

La Candelaria<smiles></smiles>

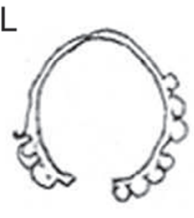

L

Fundo San Jorge

(Angol)

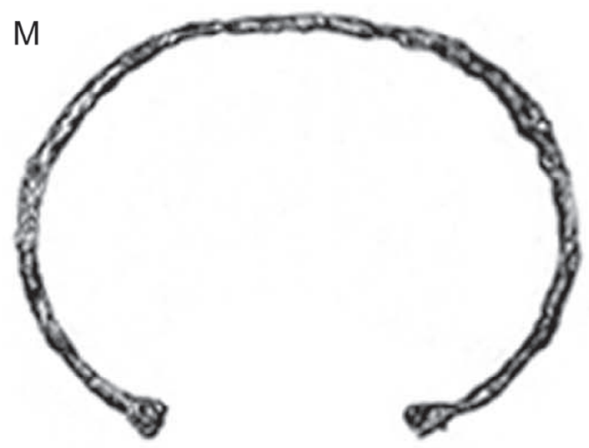

Co-2

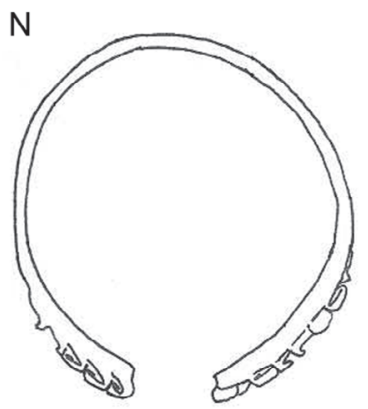

Isla Mocha (sin procedencia)

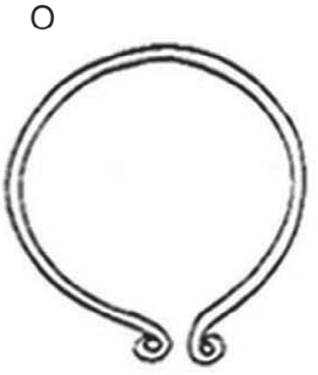

Padre Las Casas
$\mathrm{P}$<smiles>C1=C=CC=C=CC=C=1</smiles>

Q<smiles>C1=CC=C2C=CC=CC=C2C=C1</smiles>

Fundo Las Moras (Angol)

$\mathrm{R}$

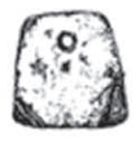

P12-1 (Isla Mocha)

Figura 1. Piezas de la tradición de trabajo de metales El Vergel. A-F: Aros cuadrangulares con muesca. G-I: Aros circulares planos. J-L: Aros circulares simples. M: Pulsera. N-O: "Aros circulares simples-Pulseras”. P-Q: Anillos. R: Pendiente. Las piezas E, F, H e I están incompletas. El aro de Ralipitra I es incluido aquí, pese a que su condición prehistórica o histórica no está del todo definida. C y O fueron tomadas de Gordon (1978); D, K y L fueron tomadas de Bullock (1970).

El Vergel's metalworking tradition artifacts. A-F: Notched quadrangular earrings. G-I: Flat circular earrings. J-L: Simple circular earrings. M: Wristband. N-O: "Simple circular earrings-Wristbands": P-Q: Rings. R: Pendant. Artifacts E, F, H, and I are incomplete. The Ralipitra I earring is included here, although its prehistoric or historic nature is unclear. $C$ and $O$ are from Gordon (1978); D and K are from Bullock (1970). 


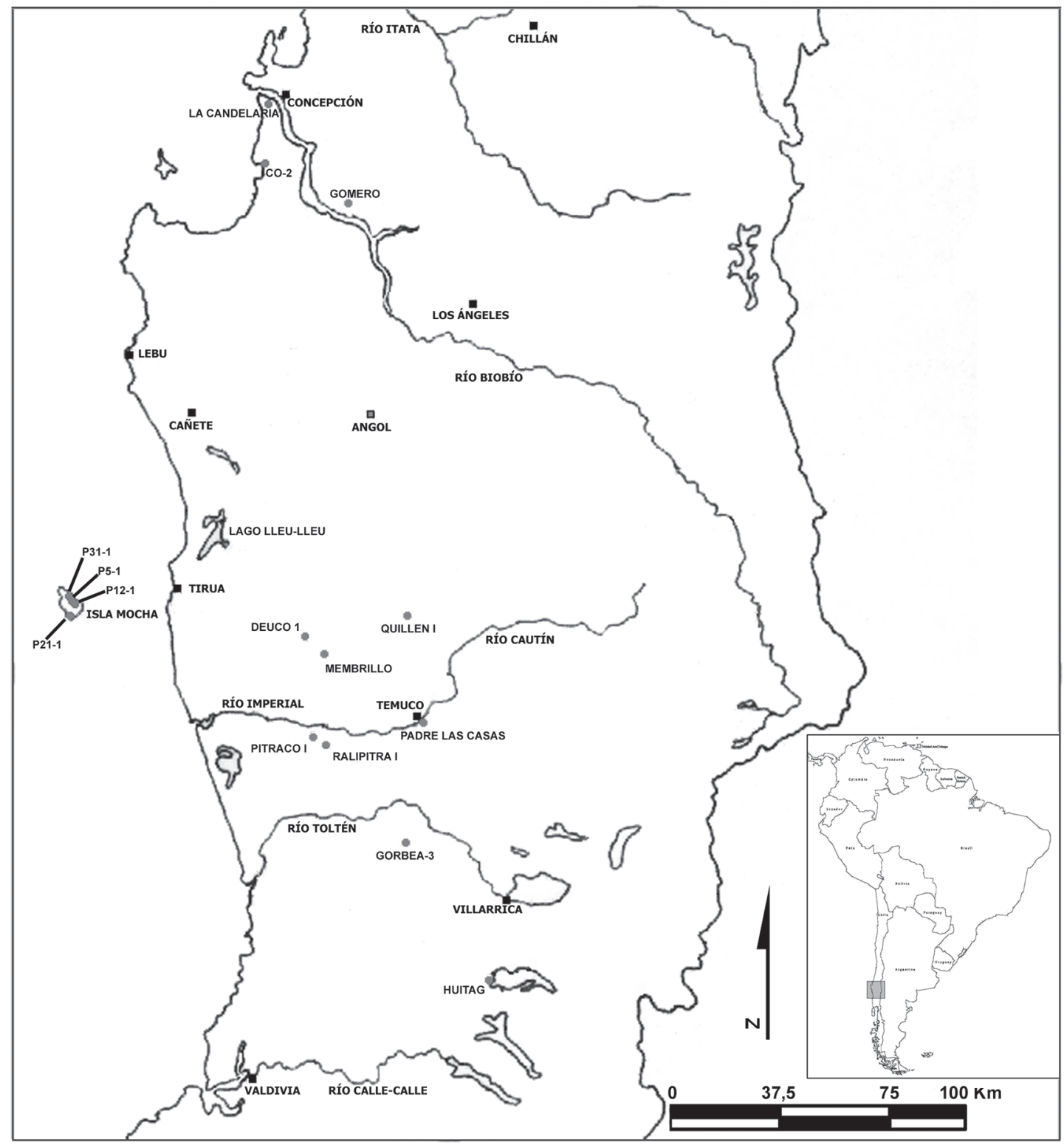

Figura 2. Mapa con los sitios y localidades arqueológicas mencionadas en el texto. Map showing the archaeological sites and localities mentioned in the text.

ocurrido entre 1550 y 1850 d.C., y demuestran lo fútil de buscar establecer el año (o incluso la década o siglo) en que desaparece la tradición de trabajo de metales El Vergel y surge la Platería Mapuche. De hecho, al momento de abordar los contextos materiales preferiremos decir que las piezas son más afines a una u otra tradición, pues encasillarlas implicaría negar el proceso del que ellas son testimonio.

Por último, debido a que la tradición de trabajo de metales El Vergel es nuestro punto de origen y que esta corresponde a elementos de adorno (como lo es también gran parte de la Platería Mapuche), al abordar la evidencia histórica nos enfocaremos primordialmente en dicho universo de artefactos. Sin embargo, esto no implica que desconozcamos la totalidad de las manifestaciones del trabajo de metales de tiempos históricos de la Araucanía. Del mismo modo, si bien esta revisión se centrará en el territorio del Complejo El Vergel, esto no busca omitir los vínculos que existieron y existen con los 

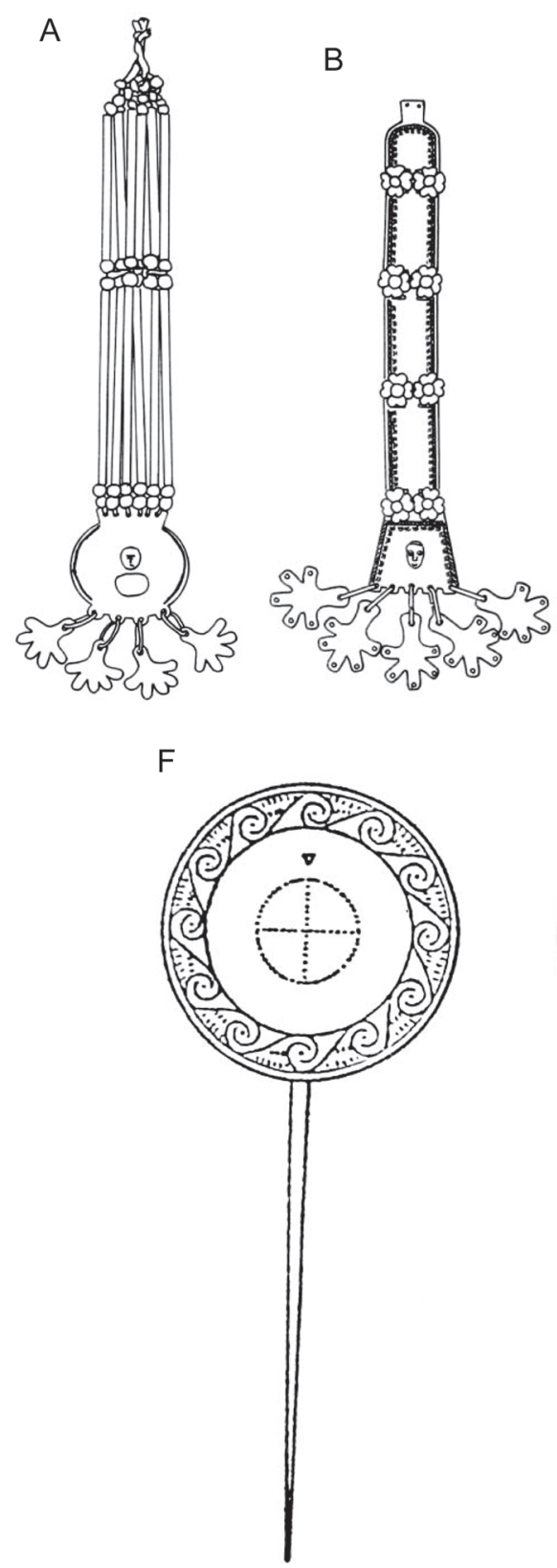

C

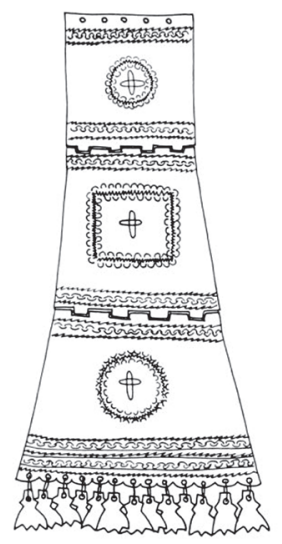

G

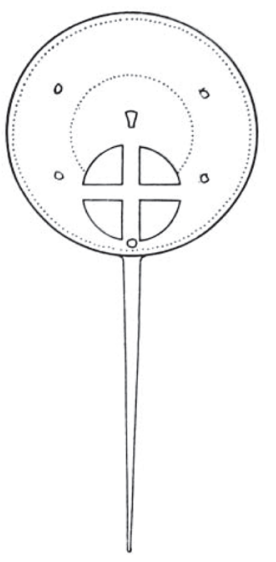

D
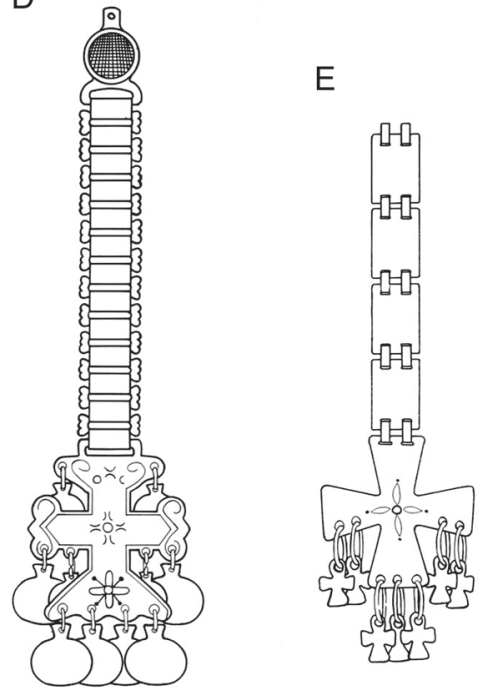

$\mathrm{H}$

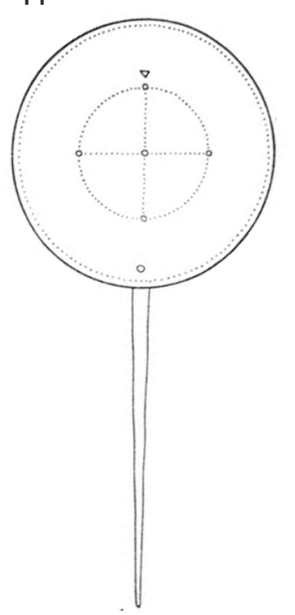

Figura 3. Piezas de la Platería Mapuche. A-C: Sikil. D-E: Trapelakucha. F-H: Tupu. Las imágenes fueron tomadas de Morris (1997). Las piezas no están a la misma escala.

Mapuche silverwork artifacts. A-C: Sikil. D-E: Trapelakucha. F-H: Tupu. Images from Morris (1997). Artifacts are not at the same scale.

grupos que habitaron más al sur del río Toltén o en los territorios cordilleranos y transcordilleranos al oriente.

A continuación los datos del registro arqueológico e histórico. Es importante aclarar que para ambos registros se ha dado mayor crédito a las ocasiones en que las piezas son descritas o ilustradas, y no solo mencionadas. Ello pues los términos usados para nombrar las piezas son de por sí poco claros o bien no son siempre coincidentes. Más aun, estos han cambiado en el tiempo, situación ya referida por Guevara (1929:278) en la primera mitad del siglo XX. 


\section{El Registro Arqueológico}

Abordar el registro arqueológico del período 1550-1850 d.C. supone varios problemas. El origen de estos es principalmente que la investigación arqueológica en el Sur de Chile ha estado concentrada en los períodos prehistóricos. Como consecuencia de esto, los escasos, aunque emblemáticos, sitios arqueológicos de tiempos históricos $-\mathrm{O}$ al menos considerados así- tienen asignaciones cronológicas no del todo confiables, sus asociaciones contextuales son ambiguas y sus materiales han sido estudiados de forma parcial. Sin perjuicio de esto, dichos sitios son una valiosa y fundamental fuente de información.

Los sitios arqueológicos tradicionalmente considerados como históricos y que contienen piezas de metal son Huitag (Menghin 1959-60:8789), Gomero (Seguel 1968), Membrillo (Reymond 1971), Gorbea-3 (Gordon et al. 1972-73), Quillen I (Valdés, Sánchez y Inostroza 1985), Ralipitra I (Valdés, Sánchez y Inostroza et al. 1985), Pitraco I (Inostroza 1985; Inostroza y Sánchez 1985, 1986; Sánchez 1985) y Deuco 1 (Inostroza y Sánchez 1986; Sánchez et al. 1985) (Figuras 4 y 5). Las descripciones de estos sitios (Tabla 1) se atienen a lo indicado en los respectivos trabajos, los que, entre otros aspectos, otorgan una gran condición de indicador cronológico y cultural a la cerámica "Valdivia" o decorada rojo sobre blanco. Es importante señalar que dichas investigaciones anteceden a los estudios de Adán y Mera (1997) y Adán et al. (2005), y por tanto lo indicado en cada trabajo apela a lo que cada autor entendía en aquel momento por cerámica Valdivia. Estas descripciones son complementadas con información de una revisión museográfica realizada en 2002 y 2003 (Campbell 2004).

El registro arqueológico muestra entonces una variedad de piezas metálicas tanto afines a la tradición de trabajo de metales El Vergel como a la Platería Mapuche, incluso coexistiendo en un mismo sitio. Estas piezas aparecen en cementerios -algunos realmente muy densos- o en entierros de tipo cista, canoa y directo, además de un sitio doméstico como Quillen I. Por su parte, la adscripción cronológica dada a estos sitios descansa en los supuestos manejados por los investigadores respecto de la temporalidad de los elementos del contexto (incluidas las piezas metálicas), lo que en algunos casos fue complementado con indicaciones dadas por los lugareños respecto del tiempo de uso de los cementerios. Este conjunto de factores apunta entonces a la dificultad de asir este variopinto registro y perfila la necesidad de reevaluarlo a la luz del conocimiento actual sobre los procesos de tiempos históricos que ocurrieron en la Araucanía, como también frente a la lectura del registro histórico.

\section{El Registro Histórico}

Este registro permitirá observar -aun si es lo que los europeos, criollos y chilenos consideraron relevante de mencionar- los cambios y continuidades que las piezas metálicas tuvieron desde la llegada europea hasta pasada la mitad del siglo XIX. Esta información esta resumida en la Tabla 2, sin embargo, recomendamos al lector interesado consultar directamente las fuentes citadas.

\section{Discusión}

Presentadas las dos líneas de evidencia, pasamos a discutirlas a la luz de los cuatro ejes propuestos: materias primas, piezas, individuos y contextos. Considerando, además, la información arqueológica existente para tiempos precontacto.

\section{Materias primas}

Como se señaló al inicio, prácticamente la totalidad de las piezas prehistóricas está manufacturada en cobre. Este es de tipo metalúrgico, demostrando un conocimiento de la tecnología de reducción de minerales. A la par de esto en el sitio P21-1 de Isla Mocha hay presencia de plata metalúrgica, la que por el fechado de su contexto (420 \pm 80 a.p., Beta-75240, carbón, $\delta 13 \mathrm{C}=-27,8 \%$ ) pudiera corresponder tanto a momentos prehistóricos tardíos o históricos tempranos (Campbell y Quiroz 2014; Sánchez 1997:128). A su vez, en consideración de la distribución que tienen las piezas metálicas prehistóricas, el origen de estas materias primas puede ubicarse tentativamente en el sector de Tirúa-Lleu-Lleu, puesto que ese es el único sector no cordillerano que presenta minerales de cobre y plata (Campbell 2005, 2008).

El registro histórico, por su parte, muestra un progresivo acotamiento hacia la presencia casi exclusiva de plata. En el siglo XVI y primeras décadas del XVII son nombrados el oro, plata, cobre y latón. Luego desde mediados y hasta fines del siglo XVII se nombra al cobre, plata y "metal 


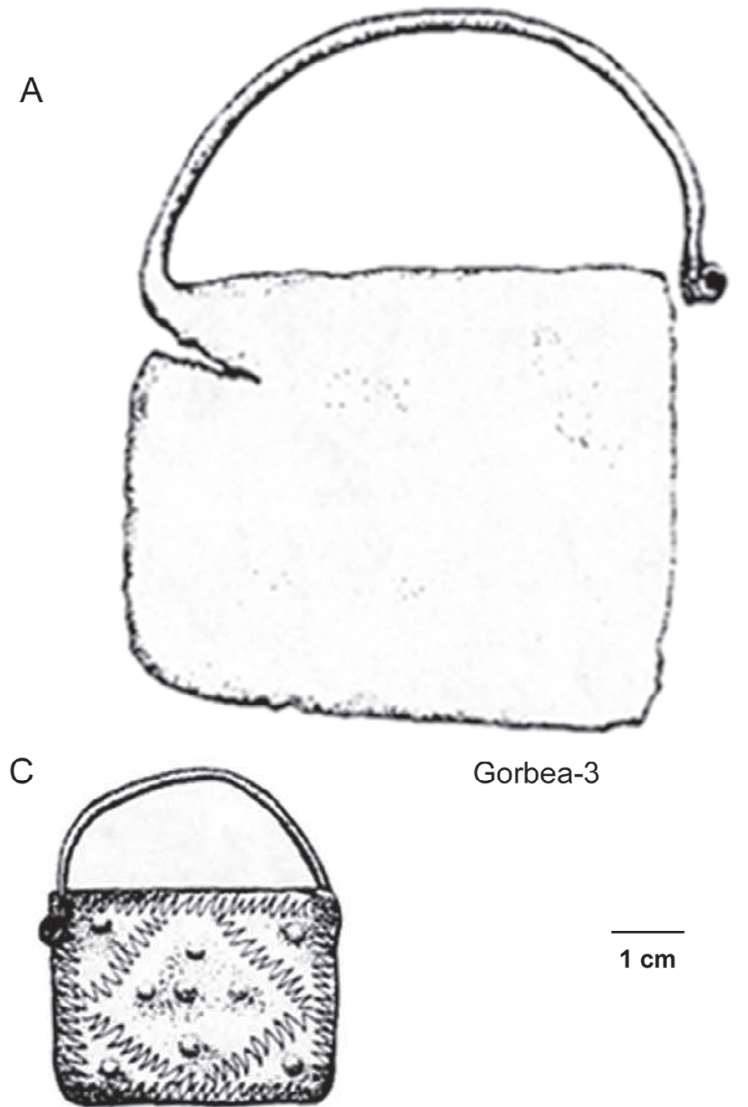

B

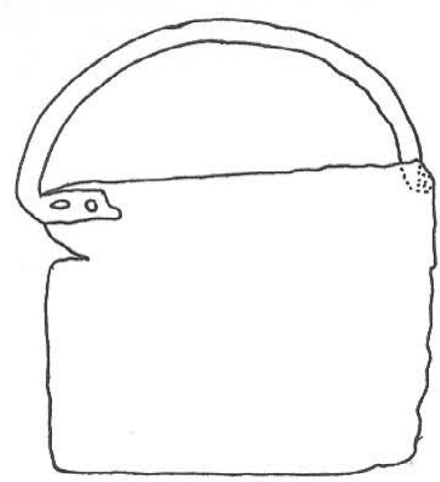

Gorbea-3

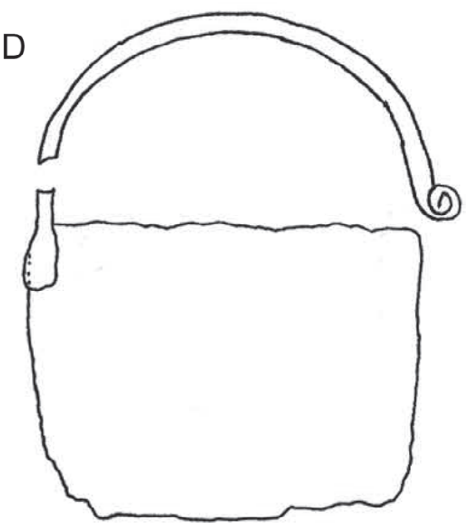

Gorbea-3

Gorbea-3

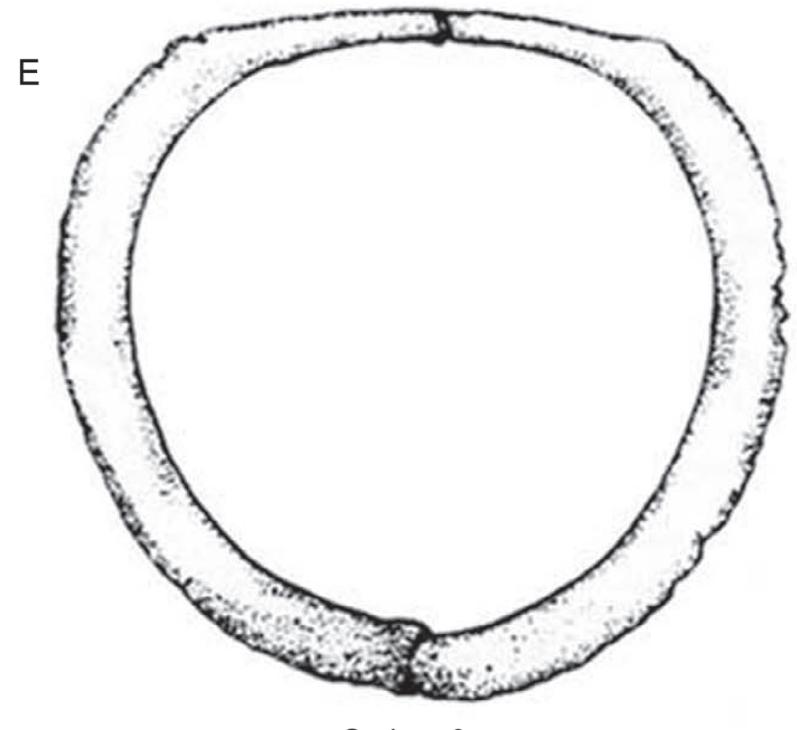

Gorbea-3

$\mathrm{F}$

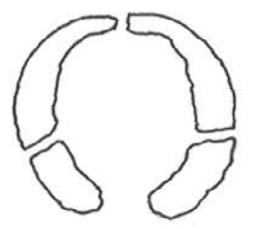

Gorbea-3

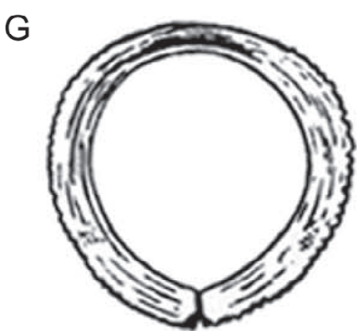

Gomero

Figura 4. Piezas metálicas de sitios de tiempos históricos. A-B: Aros cuadrangulares con muesca. C-D: Aros cuadrangulares sin muesca. E-G: Aros circulares planos. A, C y E fueron tomadas de Gordon et al. (1972-73); G fue tomada de Seguel (1968).

Historic sites metal artifacts. A-B: Notched quadrangular earrings. C-D: Un-notched quadrangular earrings. E-G: Flat circular earrings. A, C, and E are from Gordon et al. (1972-73); $G$ is from Seguel (1968). 

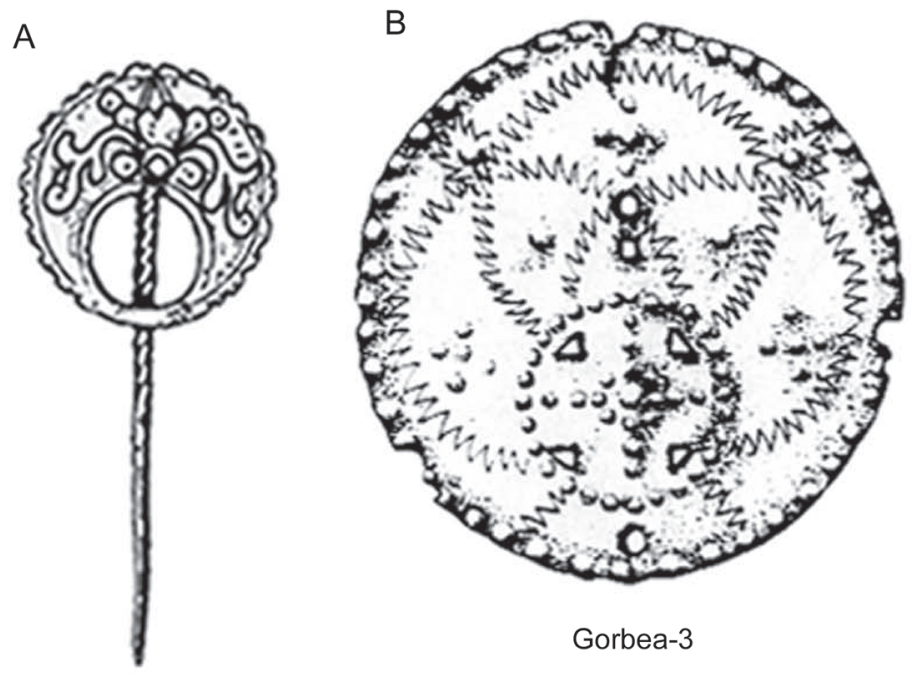

Gorbea-3

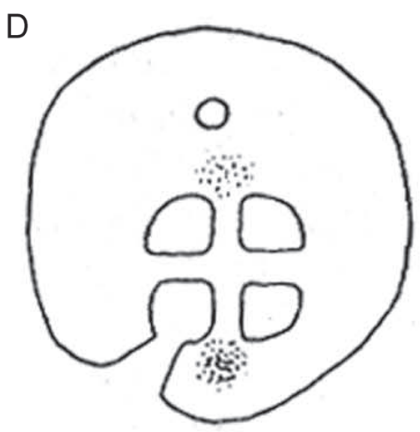

Huitag
E

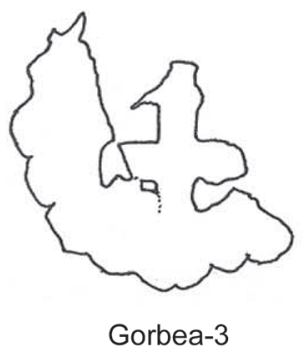

C

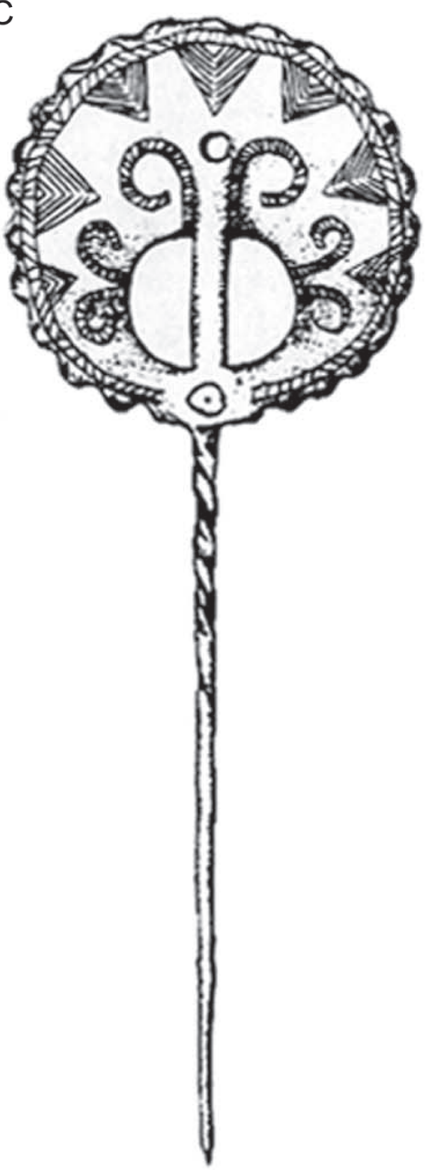

Gorbea-3

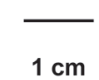

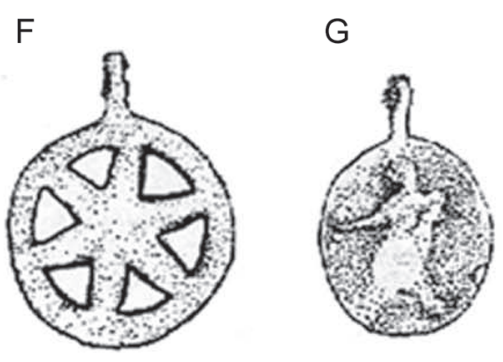

Membrillo
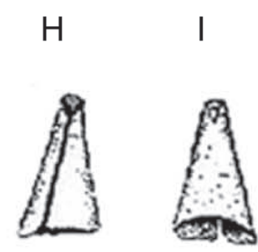

K
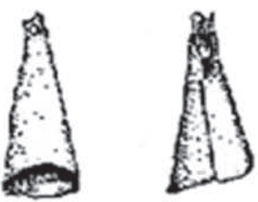

Membrillo

Figura 5. Piezas metálicas de sitios de tiempos históricos. A-E: Tupu y discos de tupu. F-G: Placas. H-K: Conos. Las piezas B, D y E están incompletas y se conservó solo el disco o parte de este. A fue tomada de Seguel (1968); B y C fueron tomadas de Gordon et al. (1972-73); D fue tomada de Menghin (1959-60); F-K fueron tomadas de Reymond (1971).

Historic sites metal artifacts. A-E: Tupu and tupu heads. F-G: Plaques. H-K: Cones. Artifacts B, D, and E are incomplete, and only the head or part of it is present. A is from Seguel [1968]; D is from Menghin (1959-60), F-K is from Reymond (1971). 


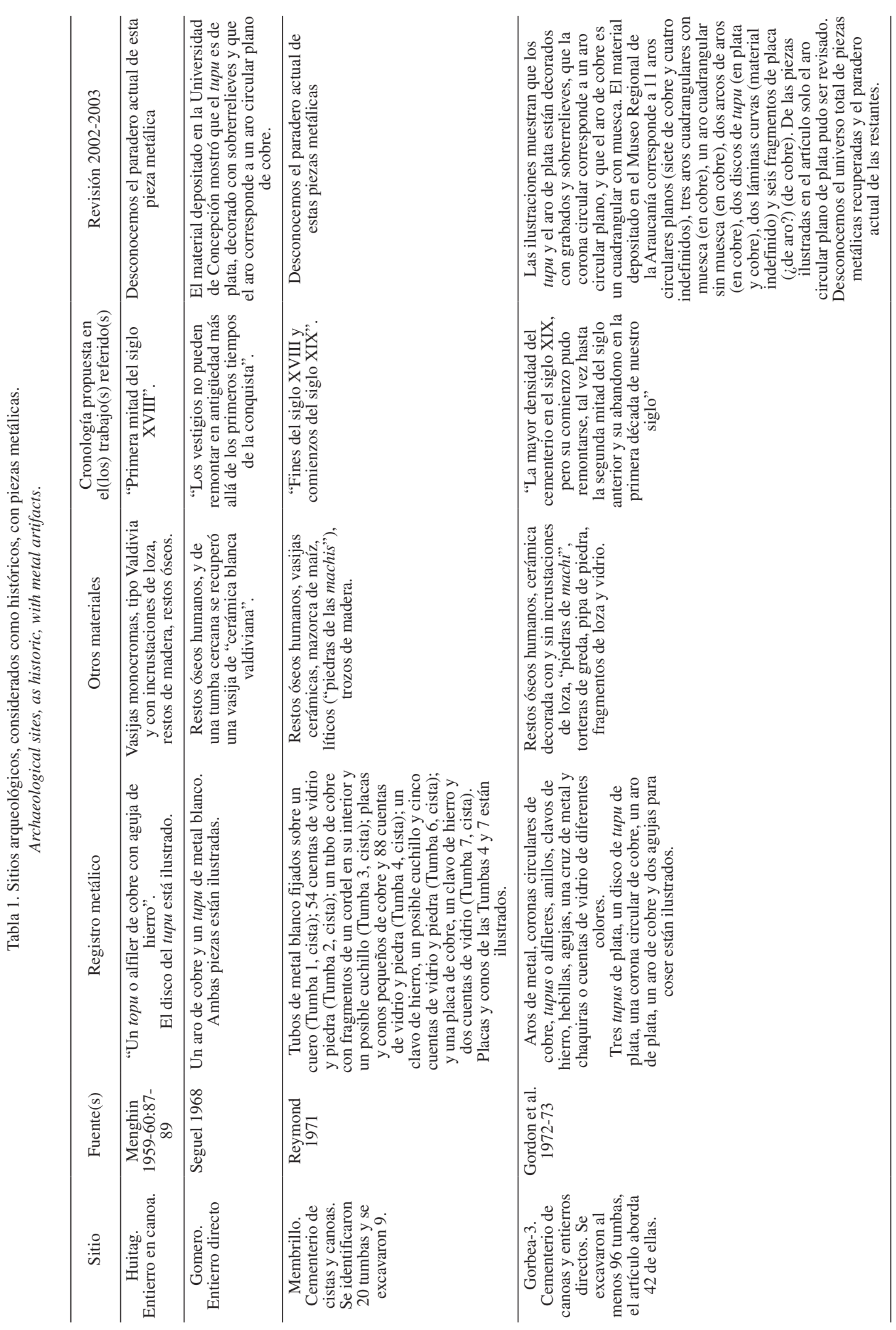




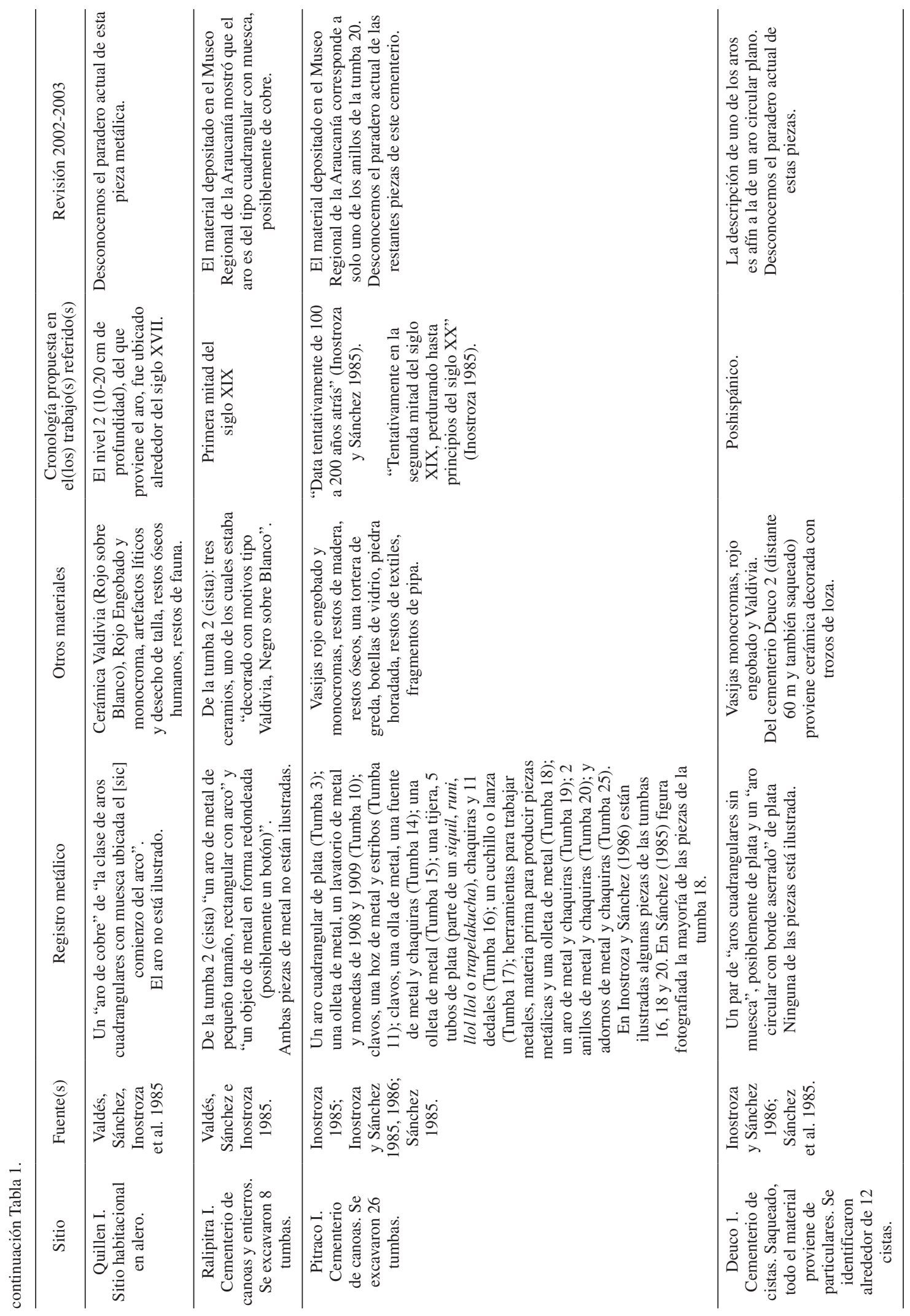


de vacinica", siendo el oro nombrado con sentido de algo antiguo y en desuso. Durante el siglo XVIII ya no se menciona el oro mientras la plata pareciera popularizarse, aunque también se indica al cobre y latón. Finalmente, durante el siglo XIX parece haber una masificación de la plata, aunque el cobre sigue siendo utilizado.

Desconocemos si la mención al uso de oro refleja una realidad o solo el ansia de los europeos de verlo en todas partes. A su vez, el "metal de vacinica" y el latón seguramente refieran a una aleación de cobre o plata de baja calidad. Junto con estos materiales es nombrado también el hierro desde el siglo XVI, en la forma de espadas, clavos, celadas, cotas, los que son reutilizados como piezas de vestir o como parte de armas. A su vez, el registro arqueológico muestra casos en los que hay solo piezas de cobre (Huitag, Quillen I, Ralipitra I), casos en que coexisten piezas de cobre y plata (Gomero), casos en que coexisten piezas de cobre, plata y hierro (Membrillo y Gorbea-3), casos en que coexisten piezas de plata y hierro (Pitraco I) y casos con solo piezas de plata (Deuco 1). A su vez, Membrillo presenta cuentas de piedra y vidrio, mientras Gorbea-3 tiene solo de vidrio.

Desde ambos registros se observa que nunca hay un completo reemplazo del cobre por la plata, sino más bien una coexistencia. De todas formas, el registro histórico tiende a mostrar un aumento en la preponderancia de la plata en el tiempo. Respecto al registro arqueológico hay que ponderar el que se cuente con casi exclusivamente contextos funerarios o, en algunos casos, con solo un par (o menos) de piezas por sitio o contexto. Al mismo tiempo, consideramos que abordar el tema de las materias primas solo desde un criterio de presencia o ausencia, no es del todo adecuado.

Debido a esto se torna clave considerar los medios de aprovisionamiento de metales utilizados. En este sentido, el registro histórico -especialmente de los siglos XVI y XVII- enfatiza la profusión de minas de oro, plata y cobre en la Araucanía. Sin embargo, si bien nuestra revisión (Campbell 2004, 2005) sobre los yacimientos mineros muestra que efectivamente el oro es bastante ubicuo, los yacimientos de cobre y plata, por el contrario, figuran concentrados en la cordillera andina y en el sector de Tirúa-Lleu-Lleu. Por otra parte, desde el siglo XVIII empieza el tráfico de "pesos fuertes" hacia el interior de la Araucanía (Aldunate 1983; Morris 1997), los que eran utilizados por los plateros para la manufactura de piezas. A su vez, esta última situación contrasta con la indicación de que los plateros mapuche obtienen su material desde minas (Housse 1940:294; Joseph 1928:124; Treutler 1958[1863]:296-429).

Por último, ya que son cuatro los metales más referidos (cobre, plata, hierro y oro), es posible que cada uno haya tenido devenires históricos de aprovisionamiento distintos e independientes. Sin embargo, debido al escaso desarrollo de la investigación y el carácter fragmentario de la información, es difícil plantear algo al respecto sin que suene a especulación. Por tanto, lo que presentaremos, con relación al devenir en tiempos históricos de estas materias primas, debe ser entendido más bien como hipótesis factibles de ser evaluadas, según nuevos datos vayan surgiendo. Para el caso del cobre es factible proponer que en los primeros tiempos poscontacto hayan coexistido dos modos de aprovisionamiento: uno desde las minas locales y posiblemente implicando reducción de minerales -y por tanto continuación de la tradición prehispánica-, y otro articulado por la presencia hispana, y con una obtención mediante el intercambio y el pillaje trans-Biobío. En el transcurso de los 300 años bajo estudio, la minería y reducción de mineral de cobre aparentemente caen en desuso, siendo reemplazadas dichas actividades por la obtención de una materia prima europea-criolla en origen. Una trayectoria similar puede ser planteada para la plata, aunque considerando el hecho de que desconocemos si los indígenas (prehistóricos o históricos) llegaron a obtenerla alguna vez vía reducción de minerales. En el caso del hierro, es muy posible que este haya sido solo obtenido desde el mundo europeo-criollo y retrabajado a fin de satisfacer las necesidades indígenas. El caso del oro puede ser similar a la trayectoria planteada para el cobre, con la salvedad de que la reducción no es necesaria y a que arqueológicamente no hay evidencia alguna directa de su uso por parte de los indígenas. Un tercer modo de aprovisionamiento pasa por el fenómeno de fundir piezas de cobre o plata ya existentes. Treutler (1958 [1863]:333) y Morris (1997) dan cuenta de esto para el siglo XIX para las piezas de plata. Por otro lado, es importante considerar que si bien en tiempos históricos se habría perdido el conocimiento respecto de la reducción de minerales, eso no implica que se haya perdido el conocimiento del manejo del fuego para precisamente, por ejemplo, fundir metales ya existentes. 


\section{Piezas}

Es necesario aclarar dos puntos inmediatamente. El primero es que las piezas metálicas de la tradición de trabajo de metales El Vergel están simplemente ausentes al año 1850 d.C., con la única excepción de los anillos. Un segundo punto es indicar que el uso de piezas metálicas indígenas para 1850 d.C. se encuentra extendido más allá del río Toltén y de la precordillera andina occidental. Por otro lado, el registro histórico recogido por nosotros da sustento a la afirmación de Morris (1997:55) de que hasta 1840, "el ajuar de la mujer araucana lo componen solo tres prendas de plata: los prendedores (tupu), los zarcillos (upul) y las sortijas (iwelkuc)". Por tanto consideramos que la gran mayoría de las piezas complejas y grandes que forman la Platería Mapuche han de ser posteriores a 1840.

Respecto de la dispersión geográfica de las piezas, por una parte, el registro histórico del siglo XVI confirma la distribución prehistórica -Isla Mocha, costa y valle entre los ríos Biobío y Toltén-, pero, por otra parte, extiende el uso de artefactos metálicos hacia sectores como Valdivia, Villarrica e incluso Chiloé. Con posterioridad las fuentes no aportan mayor claridad geográfica, refiriéndose vagamente al territorio indígena al sur del Biobío. La excepción es Brouwer (1928 [1648]), quien refiere el uso de artefactos metálicos para el área de Valdivia. Por su parte, desde fines del siglo XVIII (Carvallo y Goyeneche 1876 [1796]:136; Molina 1795:222-223) aparecen menciones respecto del uso de artefactos metálicos por parte de los Pehuenche. El registro histórico del siglo XVI es así nuevamente el más disímil, pues para los siguientes siglos la evidencia pudiera ser interpretada como una progresiva dispersión desde el territorio entre el Biobío y el Toltén. En relación con las piezas mismas, la información respecto de dicho siglo es también la más difícil de ponderar, debido a que indica incluso el uso de piezas como diademas y narigueras. Las primeras pudieran corresponder a adornos cefálicos y collares de cuentas, mientras las segundas no han sido recuperadas en ningún sitio arqueológico a la fecha. Al mismo tiempo, el registro histórico del siglo XVI si es coincidente con el registro prehistórico en cuanto al uso de aros, brazaletes (pulseras) y anillos. La mención a puntas de cobre (interpretadas por nosotros como hachas de cobre) es solo indicada para el siglo XVI (Vivar 1979 [1558]:183) y hasta las primeras décadas del siglo XVII (González de Nájera 1889 [1614]:28), para luego ser solo referidas a fines del XVIII (Molina 1795:22) como algo del pasado.

Con relación al tupu de cabeza discoidal no tenemos evidencia de su uso prehistórico. A principios del siglo XVII, Ocaña (1995 [1600]:58) (Figura 6) menciona el uso del tири -incluso empleando dicha palabra-, pero no especifica su forma, siendo hasta posible que él haya aprendido esta palabra tras su paso por la región andina, y no signifique necesariamente que esta haya sido la utilizada en la Araucanía. De hecho, los tupu ilustrados en Ovalle (1646:392) (Figura 7) no son de cabeza discoidal. La primera mención y representación fehaciente del tupu de cabeza discoidal es recién de principios del siglo XVIII (Frezier 1716:65, 1902 [1716]:39) (Figura 8). Por su parte, todos los tupu de sitios arqueológicos considerados como históricos poseen cabeza discoidal; en cobre el de Huitag, en plata el de Gomero, y en plata y en cobre los de Gorbea-3. En consideración al registro histórico estos corresponderían entonces tentativamente, al menos, a un momento posterior a 1700 d.C.

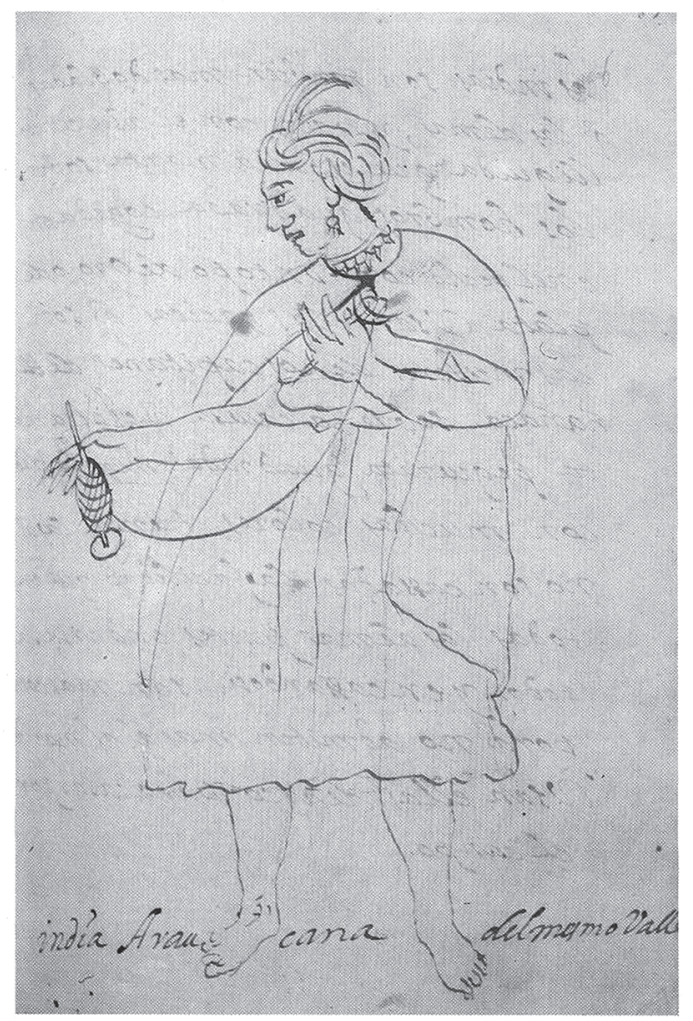

Figura 6. Uso de aros y cuentas (collar). Ocaña 1995 [1600]. Use of earrings and beads (necklaces). Ocaña 1995 [1600]. 


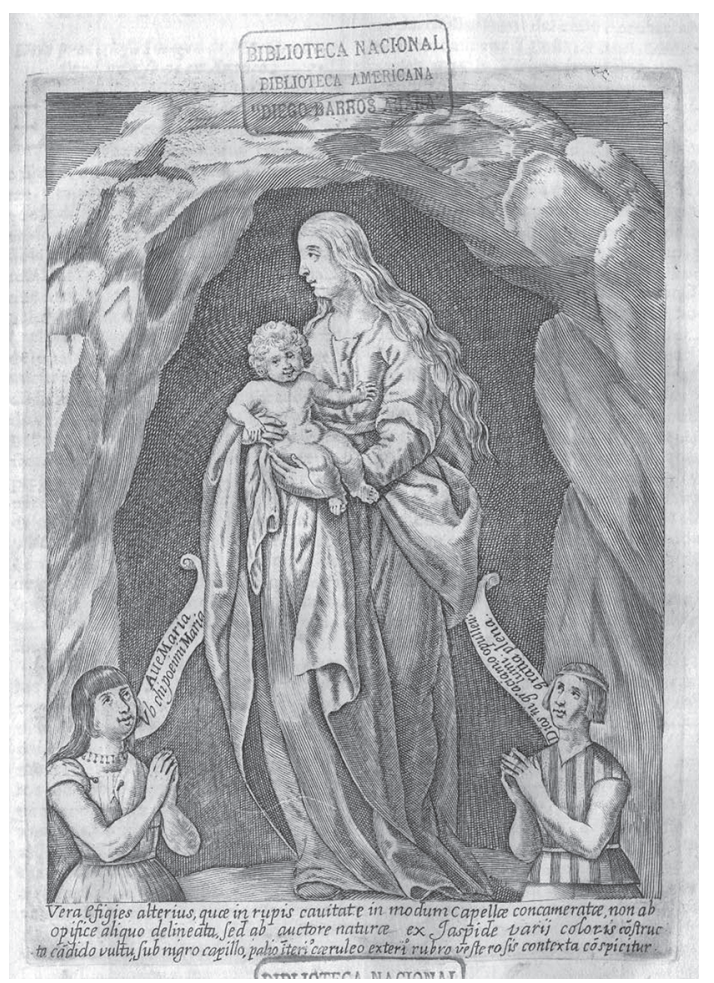

Figura 7. Uso de tupu por el individuo femenino de la izquierda. Ovalle 1646.

Tupu use by the female individual at the left. Ovalle 1646.

Morris $(1997: 66,192)$ y el catálogo de la Colección Reccius (Museo Chileno de Arte Precolombino 1983:78) presentan tири afines a los presentados por el grabado de Ovalle. Sin embargo, el primero consigna que viene de un sitio arqueológico sin aportar más datos, mientras el segundo no tiene información de proveniencia alguna.

Todo lo anterior nos lleva a plantear que tanto las hachas como los tupu de cabeza discoidal pudieran ser incorporaciones históricas. En el caso de las hachas estas desaparecen durante los siglos XVII o XVIII, mientras los tupu de cabeza discoidal se arraigan fuertemente y continúan hasta nuestros días. El caso de las hachas es sumamente interesante pues constituirían las primeras piezas volumétricas reportadas para la Araucanía, demandando además el uso de moldes. Por último, para principios del siglo XVII (González de Nájera 1889 [1614]:36) los anzuelos de cobre aún están en uso, por tanto su desaparición ocurriría con posterioridad a esta fecha.

Respecto de los aros, la primera impresión es que estos constituirían una situación de continuidad dado su uso hasta la actualidad. De hecho, Rosales

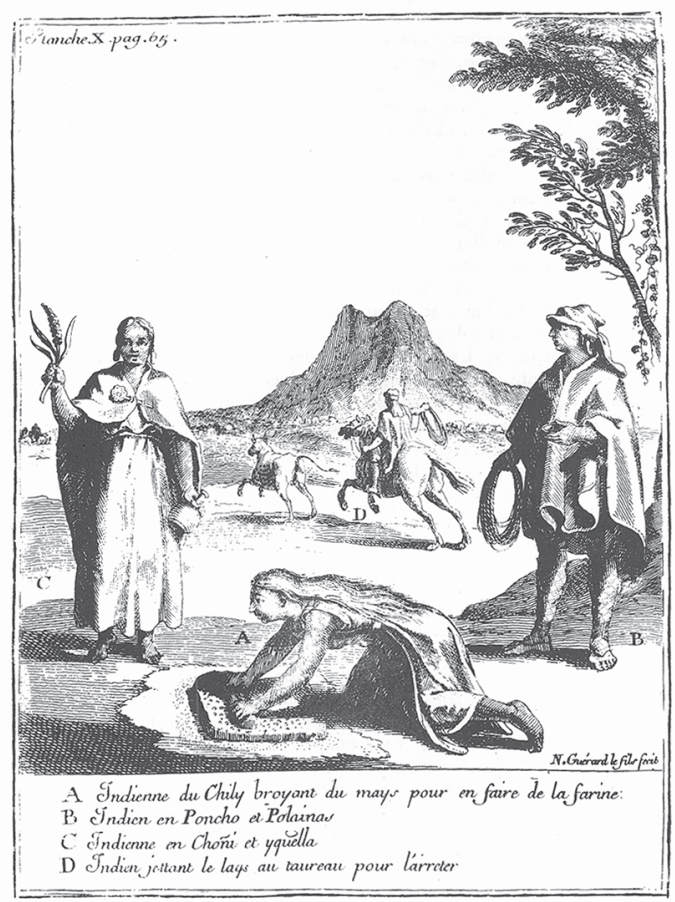

Figura 8. Uso de tupu y aros por el individuo femenino de la izquierda. Frezier (1716).

Tupu and earrings use by the female individual at the left. Frezier (1716).

(1877 [1674]:159), en la segunda mitad del siglo XVIII, los refiere como upul, que hasta hoy es una de las palabras usadas para nombrarlos. Sin embargo, una evaluación más en detalle entrega otra imagen. Los aros cuadrangulares con muesca eventualmente parecen perder su característica muesca y bien pudieran haber devenido en los aros cuadrangulares sin muesca y trapezoidales. Es en tiempos históricos que surgirían los aros semilunares, campanuliformes y con colgantes. En relación con los últimos pudiera ser significativo que Rosales mencione el uso de "arracadas", es decir, de un "arete con adorno colgante" (Real Academia Española 2001). Dicha descripción pudiera corresponder entonces tanto a unos "aros circulares simples" con cuentas engastadas, o bien a formas más complejas, que se alejan de la simplicidad de las piezas El Vergel. Por último, la descripción de González de Nájera (1889 [1614]:47) de "zarcillos [...] a modo de ruedecillas de reloj" calza bastante bien con la de unos aros circulares planos con su característico denticulado perimetral, y denotaría que a principios del siglo XVII estos seguían en 
uso. Por su parte, el registro arqueológico muestra la presencia de aros cuadrangulares con muesca en Gorbea-3, Quillen I y Ralipitra I (todos en cobre), y de aros circulares planos en Gomero (en cobre), Gorbea-3 (en cobre y material indeterminado) y Deuco 1 (en plata). Mientras hay presencia de aros cuadrangulares sin muesca en Gorbea-3 y Deuco 1. A la fecha no hay hallazgos de aros circulares simples o "aros circulares simples-pulseras" en sitios arqueológicos considerados como históricos.

La continuidad que se pudiera observar entre los aros cuadrangulares con muesca El Vergel y los aros cuadrangulares sin muesca y trapezoidales Mapuche, es sumamente interesante. Ocurre que los primeros son los únicos aros de la tradición de trabajo de metales El Vergel que aparecen en todos los sectores de la Araucanía (Isla Mocha, costa y valle) y en todos los tipos de entierros (urna, cista, canoa y entierro directo). Es decir, a diferencia de los restantes aros prehistóricos, estos son los únicos adornos que aportan una imagen de unidad a todo el territorio ocupado por el Complejo El Vergel (Campbell 2004). Por tanto, no debiera sorprendernos que esta pieza, más allá de las transformaciones morfológicas que referimos, sea la única que perduró durante los procesos de transformación políticos y sociales que ocurren en tiempos históricos (Boccara 2007 [1998]; Dillehay 2007) y que llevan que a mediados del siglo XVIII surja finalmente el etnónimo Mapuche. Dicho de otra forma, que posterior a 1750 d.C. la sociedad habría apelado para plasmar su integración étnica, a la única pieza que ya desde tiempos prehistóricos daba un cierto cariz de integración cultural a toda la población de la Araucanía.

Por último, respecto de las cuentas, los contextos funerarios El Vergel han entregado algunas cuentas de concha (Bahamondes et al. 2006) y de piedra (Gordon 1978). Si bien el registro histórico las menciona, denotando su importancia y valor para los indígenas, este no aporta detalles muy precisos sobre ellas. Por ejemplo, es difícil decir si las cuentas de piedra caen en desuso después de la segunda mitad del siglo XVII (Rosales 1877 [1674]:159) o de fines del siglo XVIII (Carvallo y Goyeneche 1876 [1796]:136). Lo que sí parece claro es que durante el siglo XIX las cuentas de vidrio se masifican en desmedro de las de piedra. El registro histórico no entrega señales respecto de que las cuentas de piedra conformasen adornos vastos y complejos, como los que durante el siglo XIX empiezan a ser producidos con cuentas de vidrio. Ejemplos de dichos valiosísimos adornos son los tapewe, guitron, meñake y traripel. Morris (1997) realiza un acabado tratamiento de estos y acompañado de un completo registro gráfico.

En cualquier caso, el registro histórico (Tabla 2) es claro en señalar que las cuentas constituyeron parte fundamental del vestir y ostentar indígenas (Figuras 9 a la 12). Es así que durante la primera mitad del siglo XIX pareciera que los distintos adornos de cuentas empiezan a incorporar plata. Para que luego, desde la década de 1850 aproximadamente, esta última desplace a las cuentas y pase a constituirse en piezas como los trarilonko ${ }^{4}$, trapelakucha y sikil manufacturados exclusivamente en plata. Morris (1997:82) indica que en dicha década empezaría una preferencia por los llef-llef (pequeños casquetes o cúpulas de plata) para el adorno femenino. Junto con esto también Morris (1997:56) plantea que, partiendo en la década de 1840: "Las primeras menciones son para joyas compuestas por millares de pequeños casquetes de plata; junto a esta variedad hacen su aparición las joyas formadas por tubos de plata, después se describen las joyas con planchas de plata y por último debutan las de cadenas".

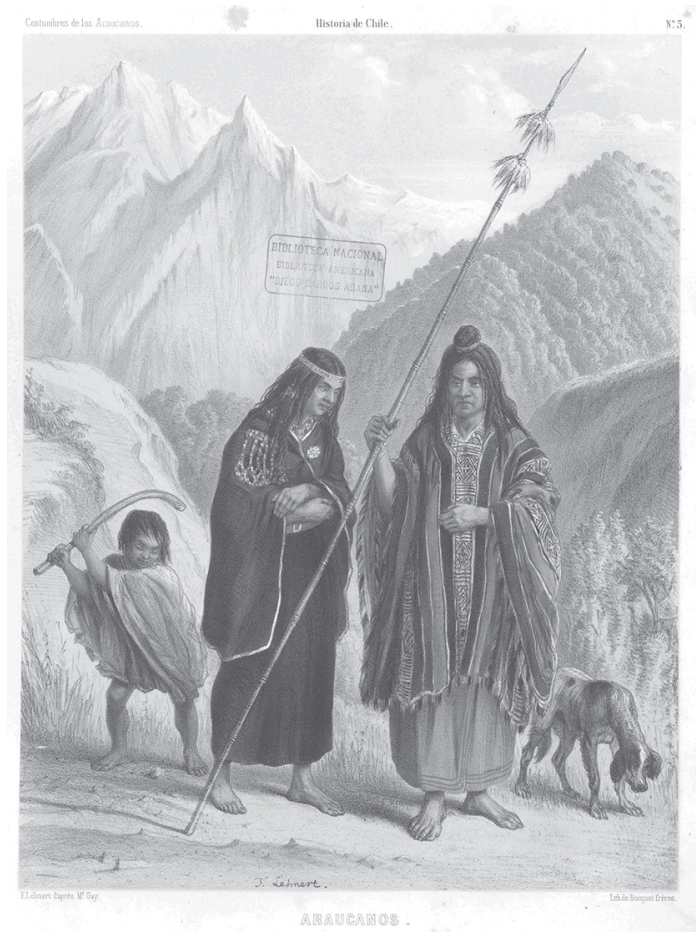

Figura 9. Uso de tupu, aros y cuentas (collares, trenzas y cintillo) por el individuo femenino al centro. Gay (1854).

Tupu, earring, and beads (necklaces, braids, and headbands) use by the female individual at the center. Gay (1854). 
Tabla 2. Registro histórico relativo al uso y presencia de piezas metálicas indígenas y cuentas.

Historical record concerning indigenous use and presence of metal artifacts and beads.

\begin{tabular}{|c|c|c|}
\hline $\begin{array}{l}\text { Fecha } \\
\text { (siglos) }\end{array}$ & Fuente & Datos \\
\hline \multirow[t]{2}{*}{ XVI } & Vivar 1979 [1558]:185, 191, 249 & $\begin{array}{l}\text { Para Concepción: "braçaletes de oro y de plata y vna manera de coronas", "al } \\
\text { pescuezo vna manera de diadema y de turquesas y de tiritas de oro", "Ellas (...) } \\
\text { traen çarcillos de cobre", en sus picas traen "enxeridos en ellas vnos hierros de } \\
\text { cobre". } \\
\text { Para Valdivia: "çarçillos de cobre, y traen en cada oreja ocho o diez, porque no } \\
\text { se les da nada por otro metal, avnque lo tienen". } \\
\text { Para Chiloé: el oro "traenlo los indios en la punta de las narizes, y es vna } \\
\text { manera de anillos, y las mujeres lo traen en las orejas por çarçillos". }\end{array}$ \\
\hline & $\begin{array}{c}\text { Mariño de Lobera, } 1865 \\
\text { [1595]:120, } 125\end{array}$ & $\begin{array}{l}\text { Para Concepción: "puntas de cobre". } \\
\text { Para Arauco, Tucapel y Cautín: "se engalanan con los más ricos atavios, usando } \\
\text { también collares, sarcillos y otras joyas de oro con piedras preciosas" }\end{array}$ \\
\hline \multirow{6}{*}{ XVII } & Ocaña 1995 [1600]:58, 68 & $\begin{array}{c}\text { Las mujeres usan "una manta sobre los hombros, cuadrada cogida en el pecho } \\
\text { con un topo de oro o de plata". } \\
\text { Primera mención de la palabra tupu. } \\
\text { Imagen: "india araucana" con un collar y un aro. No se evidencian los } \\
\text { materiales de estos. }\end{array}$ \\
\hline & $\begin{array}{c}\text { González de Nájera 1889 } \\
\text { [1614]:35, 36, 46, 47, 121, 169) }\end{array}$ & $\begin{array}{c}\text { Lanzas con puntas de cobre, anzuelos de cobre y pedazos de oro usados como } \\
\text { pesas de red. } \\
\text { Las mujeres usan zarcillos, brazaletes y gargantillas. } \\
\text { "Usan algunas mujeres zarcillos de plata hechos de cálices y patenas que } \\
\text { hubieron en el saco de las ciudades que destruyeron (...), y comúnmente } \\
\text { también traen zarcillos de latón habido en el mismo saco, hechos a modo de } \\
\text { ruedecillas de reloj, dentadas, grandes y pequeñas, y de otras formas". } \\
\text { Usan sartas de cuentas "que les sirven de ceñidores, largas de a dos y más } \\
\text { varas, y de dos dedos de ancho, compuestas de menudísimos granos ensartados } \\
\text { en hileras, que juntan unas con otras a modo de aljófar, o abalorio blanco, las } \\
\text { cuales cuentecillas son hechas de conchas marinas". } \\
\text { Menciona al herrero Nieto "quien por ser cautivo, forzaban los indios a que les } \\
\text { forjase". }\end{array}$ \\
\hline & Ovalle 1646:91, 92, 392 & $\begin{array}{c}\text { Uso y valor dado a las sartas de cuentas de conchas que se ponen al cuello. } \\
\text { Uso por parte de los indígenas en territorio hispano de "punçones de plata (que } \\
\text { llaman Topos) o de otra material". } \\
\text { Imagen: Grabado de la Virgen, con una indígena portando un collar y dos } \\
\text { tupu de cabeza pequeña sujetando parte del vestido, ambos de material } \\
\text { indeterminado. }\end{array}$ \\
\hline & Brouwer 1928 [1648]:96-97) & $\begin{array}{l}\text { Para Valdivia: en el pasado "los indios usaban trozos de él [oro] como adornos, } \\
\text { hasta el tamaño de la mitad de un dedo, que colgaban en cuerdas y colocaban en } \\
\text { el cuello y la cabeza". }\end{array}$ \\
\hline & $\begin{array}{c}\text { Núñez de Pineda y Bascuñán } \\
1863 \text { [1673]:201) }\end{array}$ & $\begin{array}{l}\text { En una "borrachera y festejo", los indígenas "sacaron también sus vestidos } \\
\text { antiguos de españoles, con sus sombreros largos de copa y cortos de faldas, que } \\
\text { parecían panes de azúcar, y algunos traían plumajes, y otros cintillos de oro a lo } \\
\text { antiguo, y el cacique llevaba sus collares de piedras, que tienen por preciosas, y } \\
\text { de los propios cintillos". }\end{array}$ \\
\hline & $\begin{array}{c}\text { Rosales } 1877[1674]: 159,1878 \mathrm{a} \\
{[1674]: 439,1878 b \text { [1674]:169) }}\end{array}$ & $\begin{array}{c}\text { "El adorno y joyas de las mugeres son llancas, que como emos dicho son unas } \\
\text { piedras toscas verdes que agujerean por medio y las ensartan, y a vezes las } \\
\text { cosen en un pedazo de paño o cartón en forma de media luna y se le ponen en } \\
\text { el pecho; sin esto, algunas sartas de cuentas de vidrio azules y verdes. Y para el } \\
\text { trenzado unas cintas que hazen de caracolitos del mar, blancos, muy pequeños, } \\
\text { que parecen cuentas de abalorio, y llaman en su lengua Cucham; y en las orejas } \\
\text { muchos zarzillos y patenas cuadradas que llaman upul de metal de vacinica o de } \\
\text { plata y cobre, y suelen traer tantos que les rompen las orejas. Y no tienen mas } \\
\text { gala ni adorno las mujeres de Chile". } \\
\text { "no es gente que guarda ni estima cosa de plata y oro, y lo que deshazian de esto } \\
\text { era para hazer punzones y arracadas a las mugeres y chapas para las cabezadas } \\
\text { de los caballos". } \\
\text { El cacique Lincopichón recibió de parte del Marqués de Baides, un bastón con } \\
\text { casquillos de plata. }\end{array}$ \\
\hline
\end{tabular}


continuación Tabla 2.

\begin{tabular}{|c|c|c|}
\hline $\begin{array}{l}\text { Fecha } \\
(\text { siglos })\end{array}$ & Fuente & Datos \\
\hline \multirow{3}{*}{ XVIII } & Frezier 1716:65, 1902:39 & $\begin{array}{c}\text { Usan "una gran aguja de plata de cabeza achatada i de cuatro o cinco pulgadas } \\
\text { de diámetro que llaman toupus". } \\
\text { "en las orejas usan placas de plata de dos pulgadas cuadradas, como } \\
\text { pendientes llamados oropellos". } \\
\text { Imagen: una indígena con aros (aparentemente pequeños) y un tupu de cabeza } \\
\text { discoidal grande. }\end{array}$ \\
\hline & $\begin{array}{c}\text { Molina } 1795: 22,57,67,109, \\
222-223)\end{array}$ & $\begin{array}{c}\text { Anteriormente los indígenas hacían de cobre "hachuelas, hachas, y otros } \\
\text { instrumentos cortantes, aunque en poca cantidad, porque se encuentran } \\
\text { raramente en los sepulcros". } \\
\text { Las mujeres usan ciertas hebillas o broches de plata con que se atan la ropa y } \\
\text { "Llevan collares y manillas de cuentas de vidrio, y zarcillos de plata en forma } \\
\text { quadrada. Todos los dedos de sus manos están, adornados de anillos, la mayor } \\
\text { parte de plata". } \\
\text { Los Apo-Ulmenes y Ulmenes usan bastones con puño de plata. } \\
\text { Primera mención a la profesión de platero entre los indígenas, y que esta se } \\
\text { distingue de los herreros. } \\
\text { Los Pehuenche "gustan de adornarse lo mismo que las mugeres", usan } \\
\text { pendientes, cuentas de vidrio y cascabeles. }\end{array}$ \\
\hline & $\begin{array}{c}\text { Carvallo y Goyeneche } 1876 \\
{[1796]: 136,160}\end{array}$ & $\begin{array}{l}\text { Las mujeres visten una "manera de capa, prendida hacia el pecho con una } \\
\text { aguja de fierro puesta en una rodela de plata, a la que le dan el nombre de } \\
\text { tupú. Se adornan con pendientes de plata, anillos de los mismo, de cobre i de } \\
\text { laton, llevan ahogadores de llancas que son esmeraldas falsas i una infinidad } \\
\text { de cuentas de vidrios". } \\
\text { Los españoles "venden frenos, espuelas, cuchillos i algunas espadas i sables" } \\
\text { burlando las prohibiciones. }\end{array}$ \\
\hline
\end{tabular}

Pérez García 1900 [1810]:61 El chamal lo "prenden por el pecho con un alfiler grande, que tiene en el remate una planchita, y le nombran tupu".

"A sus zarcillos llaman upid, y a las chaquiras con que adornan cabeza y cuello nombran llancas".

Poeppig 1960 [1829]:398, $399 \quad$ "Aros en forma de candados, pesando el par cerca de dos libras".

Las trenzas del cabello están unidas por un "cordon que llevan una gran cantidad de campanillas, sartas de vidrio y trozos de cobre pulido", cordones similares son usados en el cuello.

\begin{tabular}{cc}
\hline $\begin{array}{c}\text { Gay 1854: Costumbres de los } \\
\text { Araucanos Lámina 5 }\end{array}$ & $\begin{array}{c}\text { Imagen: Grabado "Araucanos": una indígena con un tupu de cabeza discoidal al } \\
\text { pecho y con sartas de cuentas colgando como parte del cabello o del vestido. }\end{array}$ \\
\hline $\begin{array}{c}\text { Rugendas 1842 (en Diener } \\
\text { 2012:92, 94; Poeppig 1960 }\end{array}$ & $\begin{array}{c}\text { Imágenes: mujeres indígenas con complejos adornos formados por cuentas tanto } \\
\text { para la cabeza (posiblemente un tapewe o similar), como también usados en la }\end{array}$ \\
$\begin{array}{c}\text { [1835]:357, 395; Schindler } \\
\text { cabellera, cuello, pecho, muñecas y tobillos. También se observan tupu de cabeza } \\
\text { discoidal y aros cuadrados, aparentemente todos en plata y de gran tamaño. }\end{array}$ \\
\hline
\end{tabular}

La mujer indígena: "En dos hermosas trenzas divide su pelo, que entreteje con mil cuentecitas de vidrio, i con ellas ciñe su angosta frente a la manera de los tocados o turbantes de las mujeres de Asia. Mucha chaquira i cascabeles en el cuello i pecho, grandes prendedores de plata i brazaletes de chaquira en los piés i brazos".

Smith 1855:180,181,191, 209, Los indígenas: "use a great many ear-rings, breast-pins, and other trinkets of the 303 same metal [silver]: indeed, it is the only metal which they use for ornamental purposes".

Al cabello menciona el uso de cuentas y de dedales de latón. En el cuello por su parte se usa un collar de cuero tachonado con plata, mientras en el pecho se usan sartas de cuentas, monedas y dedales. En las muñecas y tobillos se usan brazaletes y tobilleras también de cuentas.

El tupu es "a silver pin, the head of which is sometimes globular, but more frequently it is flat, and about the shape and size of a small dinner plate".

Imágenes: mujeres indígenas usando tupu de gran tamaño, aros posiblemente campanuliformes, fajas en la cintura y cuellos y adornos seguramente manufacturados con cuentas a modo de muñequeras y cubriendo la cabeza (tipo tapewe). De estos últimos y de los tupu cuelgan a su vez, conos, dedales o pequeñas medallas. 
continuación Tabla 2.

\begin{tabular}{|c|c|c|}
\hline $\begin{array}{l}\text { Fecha } \\
\text { (siglos) }\end{array}$ & Fuente & Datos \\
\hline \multirow{4}{*}{ XIX } & $\begin{array}{c}\text { "Salteo al cacique Huenul" } 1857 \\
\text { (en Morris 1997) }\end{array}$ & $\begin{array}{l}\text { Al cacique le fueron robados "cuatro tupu, tres pares de uples, una aguja de } \\
\text { plata que llaman vroñe, un tapague, dos guitrones y una arroba de chaquira", } \\
\text { todo valorizado en } \$ 127 . \\
\text { Aporta la distinción entre "plateros fronterizos" (o "maestros espueleros" o } \\
\text { "maestros estriberos") y "plateros indígenas". }\end{array}$ \\
\hline & $\begin{array}{c}\text { Treutler } 1958[1863]: 333,334, \\
401\end{array}$ & $\begin{array}{l}\text { "El adorno principal de las mujeres consistía, generalmente, en una aguja de un } \\
\text { pie de largo y del espesor de un lápiz, rematada en un botón del mismo metal, } \\
\text { del tamaño de una manzana, con la cual sujetaban la túnica; además, llevaban } \\
\text { anchos brazaletes en los brazos y los tobillos, y un gran número de objetos } \\
\text { pequeños como anillo, cruces, campanitas en las orejas o entretejidos en el } \\
\text { cabellos. Todos estos adornos eran de plata maciza, jamás usaban alhajas falsas } \\
\text { o de oro". }\end{array}$ \\
\hline & Ruiz Aldea 1902 [1868]:21 & $\begin{array}{l}\text { El manto lo "prenden en los hombros con unas agujas que denominan } \\
\text { thapelues" y que "Las mujeres de los caciques se distinguen por el adorno que } \\
\text { llevan en la cabeza, hecho de avalorios (llameatu) del que pende una sarta de } \\
\text { cascabeles o dedales, que hacen gran ruido al moverse". } \\
\text { Brazaletes de chaquiras en las piernas y brazos, y el cabello "se lo dividen en } \\
\text { dos largas trenzas, que tambien entretejen con chaquiras o lo envuelven en } \\
\text { huinchas de lana". También "llevan zarcillos en las orejas como algunos indios } \\
\text { jóvenes, o bien, unas grandes medallas de plata que llaman tupos". }\end{array}$ \\
\hline & Coña 2006 [1930]:226 & $\begin{array}{l}\text { "En tiempo muy antiguo las indigenas no poseian muchas alhajas de plata; } \\
\text { tenian el prendedor tupu y los pendientes, más no. Más numerosos eran los } \\
\text { adornos de chaquiras". Dichas chaquiras se usaban para envolver el cuello, las } \\
\text { muñecas y tobillos, hacer collares y en las trenzas del cabello. A continuación } \\
\text { se ocupa en describir el trabajo de platero y menciona piezas como los quiquil, } \\
\text { cúpulas, tupu, punzones, siquill, trapelakucha, anillos y zarcillos. }\end{array}$ \\
\hline
\end{tabular}

\section{Individuos}

Como ya se indicó, los escasos casos arqueológicos prehistóricos (Padre Las Casas, P21-1, Co-2), en que se han conservado restos óseos humanos en asociación a adornos metálicos, muestran su vinculación a sujetos femeninos o subadultos. Esta situación es refrendada para tiempos históricos por el registro histórico y arqueológico, aunque en el último caso solo en Gomero los restos óseos humanos lograron preservarse y fueron recuperados y analizados contextualmente (Gerber 1968). Sin perjuicio de esta aparente recurrente asociación, hay menciones ocasionales al uso de cuentas y aros por parte de algunos caciques (González de Nájera 1889 [1614]:47; Núñez de Pineda y Bascuñán 1863 [1673]:201). A su vez, a partir del siglo XVII empieza la mención al uso de piezas metálicas ecuestres. Esta situación denota lo planteado anteriormente por nosotros (Campbell 2004) respecto de que la riqueza y estatus del hombre pareciera estar siendo proyectado en y por medio de las mujeres y los caballos.

También respecto de los individuos, cabe preguntarse quienes son los especialistas que manufacturan las piezas metálicas. Para tiempos prehistóricos no tenemos información alguna, siendo lo más cercano el mencionar que las únicas posibles evidencias de manufactura de piezas (escorias metalúrgicas) han sido recuperadas en los sitios P31-1, P5-1 y P12-1 de Isla Mocha (Campbell 2005, 2011). Obviamente sería esperable encontrar trazas de trabajo de trabajos de metales también en el continente y más profusamente para tiempos históricos. En este contexto es importante considerar nuestro planteamiento de que los tuри y hachas pudieran ser incorporaciones históricas muy tempranas. Por tanto, la morfología y tecnología para la producción de estas piezas pudieran estar vinculadas a los movimientos poblacionales ocasionados por la desarticulación del Tawantinsuyu o al avance europeo -acompañado de indígenas más septentrionales- hacia el sur de Chile. Para principios del siglo XVII, González de Nájera (1889 [1614]:121) informa de la presencia de herreros hispanos entre los indígenas, y hacia fines del siglo XVIII, Molina (1795:109) menciona la existencia de la profesión de platero entre los indígenas, como separada de la de herrero. 


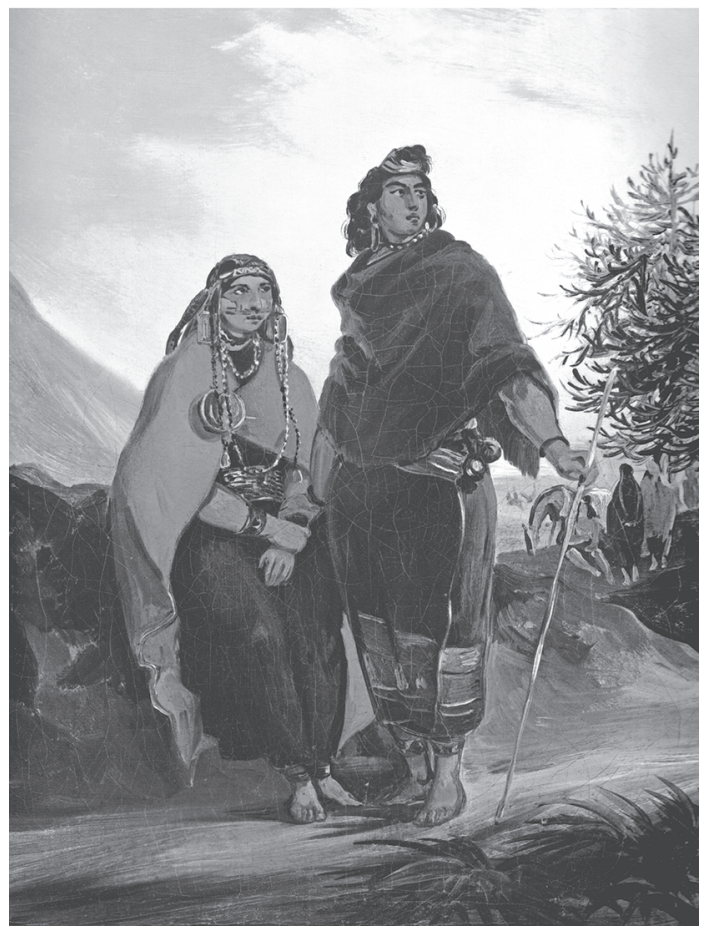

Figura 10. Uso de tupu, aros y cuentas (collares, trenzas, cintillo y pulseras) por el individuo femenino de la izquierda. Rugendas 1842 (en Diener 2012:94).

Tupu, earrings, and beads (necklaces, braids, headbands, and bracelets) use by the female individual at the left. Rugendas 1842 (in Diener 2012:94).

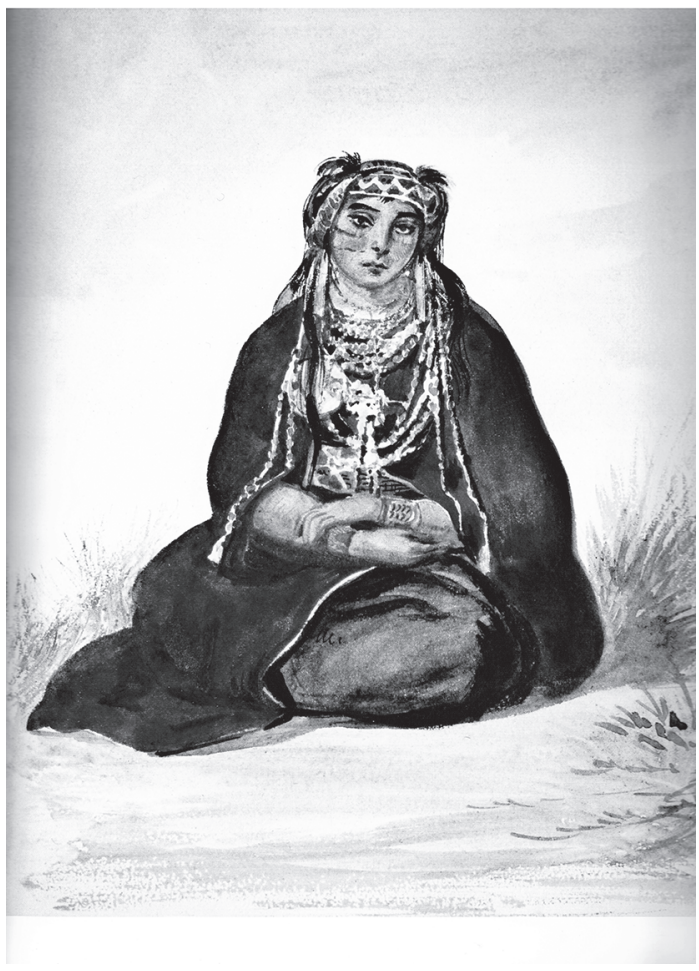

Figura 11. Uso de tupu, aros y cuentas (collares, trenzas, cintillo y pulseras) por un individuo femenino. Rugendas 1842 (en Diener 2012:96).

Tupu, earrings, and beads (necklaces, braids, headbands, and bracelets) use by a female individual. Rugendas 1842 (in Diener 2012:96).

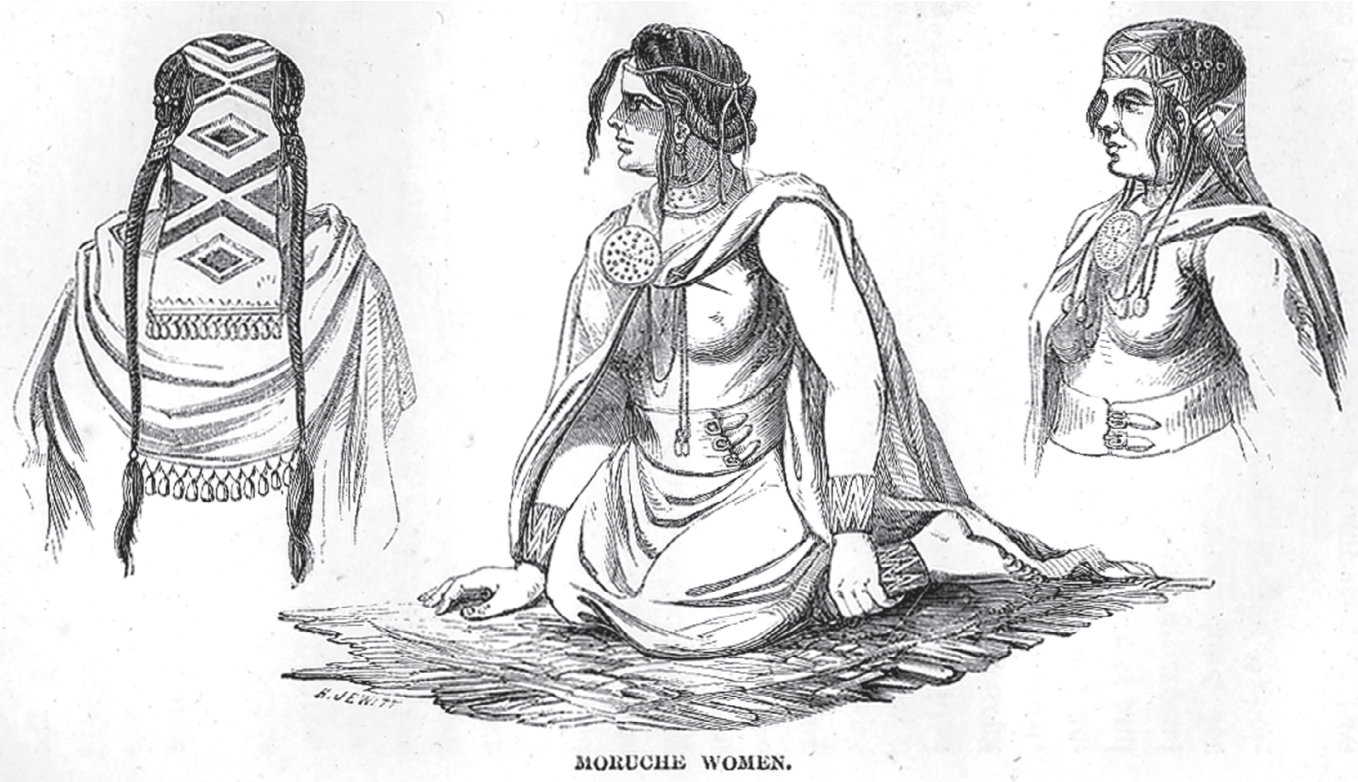

Figura 12. Uso de tupu, aros y cuentas (collares, trenzas, cintillo y pulseras) por individuos femeninos. El adorno cefálico de la izquierda es un tapewe, formado casi íntegramente por cuentas de colores. Smith 1855.

Tupu, earrings, and beads (necklaces, braids, headbands, and bracelets) use by female individuals. The head adornment at the left is a tapewe, made almost entirely from colour beads. Smith 1855. 
Desde principios del siglo XIX al menos, Morris (1997) documenta extensamente la existencia y modos de los "plateros fronterizos". Estos son orfebres chilenos que viven al norte de la Frontera, encargados de la manufactura de los elementos ecuestres y domésticos (como mates, bombillas, cuchillos, fuentes), y cuyos clientes van desde hacendados e indígenas, hasta campesinos e incluso delincuentes. Estos plateros a veces incursionaban al interior del territorio indígena a comerciar sus productos y hubo casos en que algunos de ellos se instalaban temporal o permanentemente entre los indígenas. A la par de estos habrían existido los "plateros indígenas", los que se habrían dedicado exclusivamente a la manufactura de los adornos femeninos en plata. De hecho, solo los plateros fronterizos que hubieran ganado la confianza de los indígenas podían dedicarse a manufacturar también estas últimas piezas. Del mismo modo, tal parece que hubo plateros que trabajaban al amparo de determinados caciques, como otros que trabajaban independientemente (Aldunate 1983; Guevara 1929:275; Joseph 1928; Smith 1855:180184; Treutler 1958 [1863]:333). Por último, Morris señala que la diversificación y masificación de las piezas de plata que ocurre desde 1850 es en gran parte efecto de un mayor contacto de ambos grupos de plateros y de un mayor ingreso de los plateros chilenos al territorio indígena. En este contexto, es bueno recordar que la tumba $\mathrm{N}^{\circ} 18$ de Pitraco I ha sido interpretada como correspondiendo a un platero, debido a que entre los elementos depositados había herramientas para manufacturar metales (tijeras, limas, punzones, martillo, cincel, marcador, tornillo de mano, plantillas de piezas) y materia prima (moneda, cuchara y diversos objetos metálicos).

Todo lo anterior no resuelve el misterio sobre quienes fueron los individuos que entre 1550 y 1850 d.C. están manufacturando las piezas metálicas de adorno. Sin embargo, en consideración de los antecedentes presentados más atrás, es posible aventurar que estos serían orfebres indígenas. Orfebres que de todas formas debieron haber estado en contacto y posiblemente fueron influenciados por plateros y herreros europeos cautivos en territorio indígena o que al menos incursionaban en este. Vinculado al tema de las materias primas, cabe preguntarse también si estos orfebres o plateros indígenas eran también los que laboraban las minas, reducían el mineral o si lo obtenían vía pillaje o intercambio, o si bien el aprovisionamiento de la materia prima corría por parte del cliente. Lamentablemente la información histórica no nos permite descartar ninguna de estas posibilidades o privilegiar alguna por sobre las otras.

\section{Contextos}

Como ya se ha indicado, las piezas metálicas de adorno se vincularían al mundo femenino. Por razones obvias desconocemos cuáles fueron sus contextos de uso en tiempos prehistóricos. A su vez, en tiempos históricos no hay claridad sobre si se las usaba cotidianamente o solo en ciertas ocasiones. No hay que desconsiderar tampoco, el que seguramente hubiera piezas que se usasen solo en determinadas situaciones.

En otro sentido, la depositación final de las piezas sí pareciera marcar una distinción entre lo prehistórico y lo histórico, distinción que se acrecentaría con el tiempo. Por un lado, ocurre que las piezas de la tradición de metales El Vergel sí están ingresando a los contextos funerarios. Tal es el caso de los contextos ya mencionados en cuanto se preservaron restos óseos humanos (Padre Las Casas, P21-1, Co-2), como también del sitio La Candelaria (Bahamondes et al. 2006) y de varias de las urnas funerarias reportadas por Bullock (1970) principalmente para el sector de Angol. Mientras en el otro extremo, si bien hay piezas de adorno en los sitios arqueológicos considerados como históricos, su presencia no está a la escala de lo indicado por el registro histórico. Esta ausencia pudiera ser entonces el resultado de tres situaciones. Por un lado, estar denotando que la masificación de las piezas es un fenómeno bastante tardío y que simplemente no hemos tenido ocasión de recuperar los contextos funerarios donde esas piezas fueron depositadas. Por otro lado, indicar la aparición de una estrategia de atesoramiento en vida, situación que tornó difícil, sino imposible, que estas piezas pudieran ser incorporadas en las tumbas. Por último, referir la existencia de una continua reutilización de las piezas, las que eran fundidas con el fin de crear nuevas piezas.

La segunda situación es la que nos parece que merece mayor atención. Ello pues refleja muy bien y sería consecuencia del paso desde una sociedad basada en la agricultura y la caza-recolección hacia una sociedad basada en la ganadería y el comercio (Boccara 2007 [1998]), a la par de un progresivo desplazamiento en las bases del poder desde el 
prestigio y carisma personal hacia aspectos más propiamente económicos y del surgimiento y consolidación de diferencias de estatus al interior de la sociedad indígena (Aldunate 1983). En este contexto, la depositación funeraria de la riqueza que implicaban las piezas de plata se torna una gran pérdida. En cambio, su atesoramiento se tornó coherente a los nuevos parámetros sociales y económicos que se consolidan en el siglo XVIII y que regirían esa suerte de "Edad de Oro" (Bengoa 2003:348) que va desde la década de 1810 (fines de la Colonia) y hasta la de 1860 (Morris 1997:2729). Por ejemplo, en el proceso del Cacique Huenul (Morris 1997) cada par de aros fue avaluado en $\$ 5$, siendo que un buey gordo se vendía también en dicho valor y una vaca en \$ 3 (Morris 1997:82). Por último, Schindler (1992:89-90) plantea que los indígenas se habrían percatado de que los chilenos antes y después de la Pacificación valoraban mucho más las piezas de plata que las de cuentas. Esto habría reforzado entonces el fenómeno de atesorar las primeras (para poder ostentarlas, trocarlas, empeñarlas o venderlas) y de desvalorización de las cuentas y adornos manufacturados con ellas. A esto se podría agregar la práctica de fundir las piezas ya existentes y crear nuevas (Morris 1997; Treutler 1958 [1863]:333), otorgando una razón más para que progresivamente las piezas dejasen de ser incorporadas en los contextos funerarios y su metal siguiera circulando. En relación con esto último, no podemos descontar que en tiempos prehispánicos el atesoramiento también haya ocurrido, pero aquello es muy difícil de ponderar. A su vez, es posible que las cuentas hayan sido las atesoradas, fenómeno que pudiera ayudar a explicar entonces su escasez en los contextos funerarios prehistóricos.

Por último, el hecho de que a la fecha los contextos prehistóricos hayan entregado más piezas que los contextos históricos - pese a lo indicado por el registro histórico, una mayor disponibilidad de materia prima y una mayor facilidad para obtener esta-, es sorteada si consideramos la gran cantidad de piezas históricas, mayormente manufacturadas en plata (por tanto, más afines a la Platería Mapuche), depositadas en museos y colecciones. Estos últimos se han convertido así en el contexto de depositación final de gran parte del trabajo de metales histórico de la Araucanía.

La revisión de la evidencia a la luz de los cuatro ejes mencionados, permite ver las continuidades y discontinuidades del trabajo de metales en la Araucanía, específicamente de los elementos de adorno. Estos elementos, pese a presentar un desplazamiento desde el cobre y las cuentas hacia la plata como principal soporte, siguen estrechamente vinculados al mundo femenino. A su vez, este cambio en las materias primas está ligado a los procesos de transformación social y política, que respondiendo a dinámicas internas -de raíz prehistórica- fueron poderosamente alimentados por la llegada europea y la creación de La Frontera. En este proceso participarían precisamente tanto orfebres indígenas como hispanos-criollos-chilenos, los que siguiendo y acomodando las pautas estéticas de ambos mundos producirían los cambios en el universo de piezas manufacturadas (tanto metálicas como de cuentas). Por último, los contextos de depositación son testimonio de las modificaciones en la valoración y uso que las piezas tuvieron entre 1550 y 1850 d.C.

\section{El registro arqueológico revisitado}

La discusión desarrollada más atrás permite, a modo de corolario, retornar sobre los sitios arqueológicos ya expuestos. Como se señaló, estos presentan problemas como su escasa claridad temporal, el uso de indicadores que han demostrado ser muy ambiguos o vagos cronológicamente (la cerámica decorada rojo sobre blanco, formas cerámicas, tipos de entierros) y asociaciones contextuales no muy claras o inciertas (sitios saqueados, sitios que pudieran ser multicomponentes).

En este sentido Quillen I y Ralipitra I, en consideración de lo que figura en los artículos y nuestro conocimiento actual de la arqueología de la Araucanía, perfectamente pudieran ser sitios prehistóricos. En el otro extremo, Pitraco I apunta claramente a ser un sitio de fines del siglo XIX e inicios del siglo XX. Ello deja a Huitag, Gomero, Membrillo, Gorbea-3 y Deuco 1 en una situación intermedia.

Gorbea-3, pese a que por ahora desconocemos sus asociaciones contextuales exactas, parece ser un sitio clave. Ello pues presenta piezas afines a la tradición de trabajo de metales El Vergel (aros cuadrangulares con muesca, aros circulares planos) como a la Platería Mapuche (aros cuadrangulares sin muesca, tири de plata). Esta situación es seguramente consecuencia de tener una gran cantidad de tumbas, lo que a su vez pudiera denotar que fue ocupado por varias generaciones, otorgando así una ventana temporal más amplia que la que proveen 
los otros sitios referidos. De hecho, las piezas -o alguna de ellas- que aparecen en Huitag, Gomero, Membrillo y Deuco 1 también están presentes en Gorbea-3. Por tanto, ahora se torna necesario buscar ordenar estos cuatro últimos sitios. A continuación indicamos nuestra propuesta tentativa respecto de la ubicación cronológica de las piezas metálicas y los sitios arqueológicos (Figura 13).

- Huitag, la presencia de un tupu de cobre lo aleja del paradigma de la Platería Mapuche, sin embargo este es de cabeza discoidal. Podría ubicársele en el siglo XVIII.

- Gomero, con un tupu de cabeza discoidal de plata y un aro circular plano de cobre, comparte con Gorbea- 3 el hecho de presentar elementos de ambas tradiciones. Es posible ubicarle entre 1650 y 1750 d.C.

- Membrillo, con un gran conjunto de piezas metálicas, ninguna afín a la tradición de trabajo de metales El Vergel, y con unas pocas más cercanas a la Platería Mapuche. Pudiéramos ubicarlo entre 1750 y 1850 d.C.

- Deuco 1, con un aro circular plano y un aro cuadrangular sin muesca, ambos en plata, es similar a Gomero y Gorbea-3. Es posible ubicarle entre 1650 y 1750 d.C.

Debido a lo anterior, Gorbea-3 pudo haber sido utilizado entre 1650 y 1850 d.C. Esta asignación lo ubica en una posición coherente tanto del punto de vista de su evidencia material, como del fenómeno de atesoramiento de piezas que hemos planteado.

En este ejercicio de ubicación cronológica es clave, sin embargo, ponderar lo pequeña de la muestra, el hecho de que estos contextos quizás no sean los más representativos de su tiempo, y que nuestra estimación está basada principalmente en la descripción de los materiales hecha en los artículos.

Del mismo modo, nuestra discusión permite también revisitar la periodificación propuesta por Reccius (1983). Desplazaríamos el inicio de su "Segunda Época" (comienzos del siglo XVIII) hacia fines del siglo XVIII o incluso comienzos del siglo XIX. A su vez, algunos elementos de su "Tercera Época" (comienzos del siglo XIX a fines del siglo XIX), como los trarilonko y trapelakucha los consideraríamos más propios de su "Cuarta Época" (fines del siglo XIX).

\section{Conclusión}

La discusión estructurada permite vislumbrar que al sur del Biobío y tras la llegada europea existió una sociedad inserta en la historia y su contexto social, político y económico más amplio. Es una sociedad que para 1850 obviamente no es la misma de 1550. Claramente hay aspectos que permiten trazar una continuidad con el pasado, pero otros son un producto de tiempos históricos generados

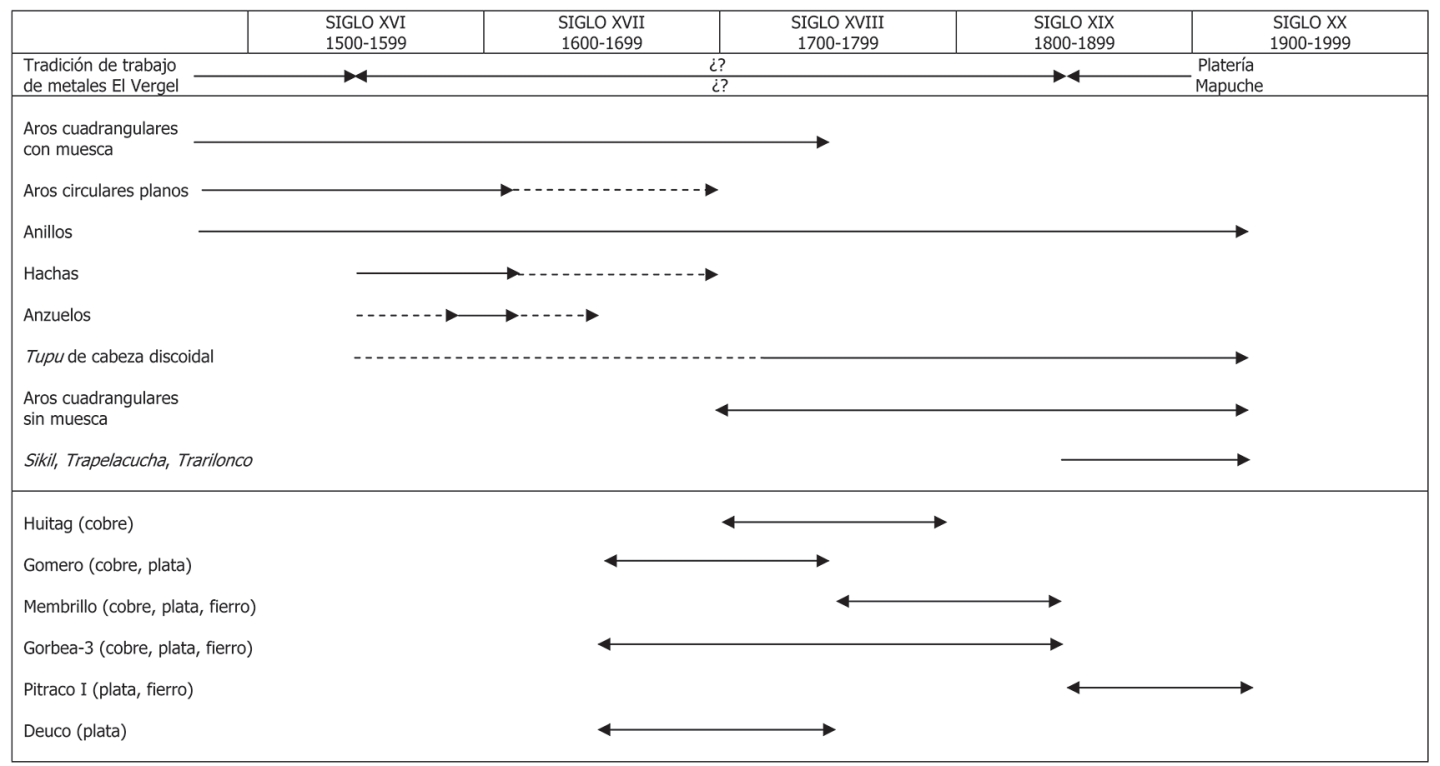

Figura 13. Propuesta de ubicación cronológica para las tradiciones, piezas y sitios discutidos.

Proposed chronological placement for the discussed traditions, artifacts, and sites. 
a partir del contacto (sea este directo, indirecto, mediado; pacífico, violento, consensuado) entre culturas y sus propias dinámicas internas.

La consideración del registro histórico a la par del registro arqueológico permite iluminar ambos registros. Por un lado, el primero es claro en indicar que hasta 1800 la industria en plata, que nos parece tan característica del mundo Mapuche, está aún en ciernes, y que por tanto, todo su esplendor ocurre en el lapso de menos de un siglo. El registro histórico permite también mirar con nuevos ojos los sitios arqueológicos que han sido considerados como históricos. Por su parte, el registro arqueológico entrega información en relación con aspectos en que el registro histórico es poco claro o ambiguo, como respecto de sus modos de depositación o la coexistencia y naturaleza de piezas de distintas tradiciones.

Dicho esto, la Platería Mapuche es heredera tanto de la tradición de trabajo de metales El Vergel como de la industria de cuentas. De la primera provendrían más que nada los aros y anillos, mientras que de la segunda los adornos cefálicos y pectorales. A su vez, estos tres referentes están cruzados por la llegada europea y las consecuencias sociales, políticas, económicas y demográficas que este acarreó en el devenir poscontacto de las tecnologías indígenas. Esto se refleja en la aparición de las hachas de cobre y el tupu de cabeza discoidal, el ingreso masivo de cuentas de vidrio, el diseño de nuevas formas de aros y la modificación en los modos de aprovisionamiento de materia prima y manufactura de piezas.

Es necesaria una investigación más a fondo, enfocada en las piezas y contextos mismos, que considere aspectos como la manufactura (gestos y detalles técnicos) y la composición química de estas. Lo que posibilitaría caracterizar más cabalmente las dos tradiciones de trabajo de metales que se ha discutido y establecer puntos de contraste y similitud más claros entre ellas. Es también fundamental una reevaluación contextual de la totalidad de los materiales (cerámicos, líticos, textiles, restos óseos humanos, etc.) recuperados en los sitios considerados como históricos.

Agradecimientos: A los proyectos FONDECYT 3130515 y 1020272 . A Fernanda Falabella, Andrés Troncoso y María Teresa Plaza por sus acotaciones y recomendaciones. A Valentina Figueroa y Diego Salazar por invitarme a participar en este número. A los dos evaluadores anónimos, cuyos comentarios ayudaron a mejorar ciertamente este trabajo.

\section{Referencias Citadas}

Adán, L. y R. Mera 1997. La tradición cerámica bícroma rojo sobre blanco en la región centro-sur: Los estilos Vergel y Valdivia. Propuesta tipológica morfológica-decorativa de la alfarería. Informe Proyecto FONDECYT 1950823, CONICYT y Archivo Nacional, Santiago.

Adán, L., R. Mera, M. Uribe y M. Alvarado 2005. La tradición cerámica bícroma rojo sobre blanco en la región sur de Chile: los estilos decorativos Valdivia y Vergel. Actas del XVI Congreso Nacional de Arqueología Chilena, pp. 399-410. Escaparate Ediciones y Museo de Historia Natural de Concepción, Concepción.

Aldunate, C. 1983. Reflexiones acerca de la platería mapuche. Catálogo Platería Araucana, pp. 10-14. Museo Chileno de Arte Precolombino, Santiago.

Aldunate, C. 1989. Estadio alfarero en el sur de Chile. En Culturas de Chile: Prehistoria. Desde sus Orígenes hasta los Albores de la Conquista, editado por J. Hidalgo, V. Schiappacasse, H. Niemeyer, C. Aldunate e I. Solimano. Editorial Andrés Bello, Santiago.

Aldunate, C. 2005. Una reevaluación del Complejo Cultural El Vergel. Actas del XVI Congreso Nacional de Arqueología Chilena, pp. 331-336. Escaparate Ediciones y Museo de Historia Natural de Concepción, Concepción.

Bahamondes, F. 2009. La Cerámica Prehispánica Tardía de Araucanía Septentrional: El Complejo Arqueológico El Vergel y su Relación con la Hipótesis del Proceso de Andinización. Tesis para optar al título profesional de Arqueólogo. Departamento de Antropología, Universidad de Chile, Santiago.

Bahamondes, F., C. Silva y R. Campbell 2006. La Candelaria: Un yacimiento funerario del Complejo El Vergel en el curso inferior del río Biobío. Boletín de la Sociedad Chilena de Arqueología 39:69-85.

Bengoa, J. 2003. Historia de los Antiguos Mapuches del Sur. Catalonia, Santiago.

Boccara, G. 2007 [1998]. Los Vencedores, Historia del Pueblo Mapuche en la Época Colonial. Instituto Investigaciones Arqueológicas y Museo R. P. Gustavo Le Paige S.J. Universidad Católica del Norte, San Pedro de Atacama.

Brouwer, H. 1928 [1648]. Relacion del Viaje de Hendrick Brouwer a Valdivia en 1643. Opúsculos varios de J.T. Medina, Tomo III:77-127. Imprenta Universitaria, Santiago.

Bullock, D. 1970. La Cultura Kofkeche. Boletín de la Sociedad de Biología de Concepción XLIII:1-203.

Campbell, R. 2004. El Trabajo de Metales en la Araucanía (Siglos X-XVII d.C.). Tesis para optar al título profesional de Arqueólogo, Departamento de Antropología, Universidad de Chile, Santiago. 
Campbell, R. 2005. El trabajo de metales en El Vergel: Una aproximación desde la Isla Mocha. Actas del XVI Congreso Nacional de Arqueología Chilena, pp. 379-389. Escaparate Ediciones y Museo de Historia Natural de Concepción, Concepción.

Campbell, R. 2008. El trabajo de metales en la Araucanía (siglos X-XVII d.C.): primeros resultados. En Problemáticas de Arqueología Contemporánea, editado por A. Austral y M. Tamagnini, Tomo II, pp. 501-510. Editorial de la Universidad Nacional del Río Cuarto, Río Cuarto.

Campbell, R. 2011. Socioeconomic Differentiation, Leadership, and Residential Patterning at an Araucanian Chiefly Center (Isla Mocha, AD 1000-1700). Ph.D. Dissertation, Department of Anthropology, University of Pittsburgh, Pittsburgh.

Campbell, R. y V. Figueroa 2013. Informe de piezas metálicas y restos metalúrgicos. Proyecto Fondecyt 3130515. Manuscrito en posesión del autor.

Campbell, R. y M.T. Plaza 2015. Informe de piezas metálicas de Isla Mocha y Coronel. Proyecto Fondecyt 3130515. Manuscrito en posesión del autor.

Campbell, R. y D. Quiroz 2014. Chronological database for Southern Chile $\left(35^{\circ} 30^{\prime} \mathrm{S}-42^{\circ} \mathrm{S}\right): \sim 33,000 \mathrm{BP}$ to present. Human implications and archaeological biases. Quaternary International. http://dx.doi.org/10.1016/j.quaint.2014.07.026

Carvallo y Goyeneche, V. de 1876 [1796]. Descripción históricoJeográfica del Reino de Chile. Tomo III. Imprenta de la Librería del Mercurio, Santiago.

Constantinescu, F. 1997. Reconstruir un antiguo modo de vida: un nuevo desafío desde la bioantropología. En La isla de las Palabras Rotas, editado por D. Quiroz y M. Sánchez, pp. 169193. Biblioteca Nacional de Chile y Centro de Investigaciones Diego Barros Arana, Santiago.

Coña, P. 2006 [1930]. Lonco Pascual Coña ñi tuculpazugun. Testimonio de un Cacique Mapuche. Pehuen, Santiago.

Diener, P. 2012. El Viaje de Rugendas por Chile 1834-1842. Origo Ediciones, Santiago.

Dillehay, T. 1990. Las culturas alfareras formativas del extremo sur de Chile. Gaceta Arqueológica Andina 5:101-114.

Dillehay, T. 2007. Monuments, Empires, and Resistance. Cambridge University Press, Cambridge.

Domeyko, I. 1846. Araucanía y sus Habitantes. Imprenta Chilena, Santiago.

Fontecilla, A. 1946. La platería entre los araucanos. Revista Chilena de Historia y Geografía 107:247-271.

Frezier, A. 1716. Relation du Voyage de la Mer du Sud aux Côtes du Chily et du Perou, fait Pendant les Années 1712, 1713 \& 1714. Chez Jean-Geoffroy Nyon, París.

Frezier, A. 1902 [1716]. Relación del Viaje por el Mar del Sur a las costas de Chile i el Perú durante los Años 1712, $1713 i$ 1714. Imprenta Mejia, Santiago.

Gay, C. 1854. Atlas de la Historia Física y Política de Chile. Tomo Primero. Imprenta de E. Thunot, Paris.

Gerber, M. 1968. Antropología física de los esqueletos de Gomero. Rehue 1:63-67.
González de Nájera, A. 1889 [1614]. Desengaño y Reparo de la Guerra del Reino de Chile. Imprenta Ercilla, Santiago.

Gordon, A. 1978. Urna y canoa funeraria. Una sepultura doble excavada en Padre Las Casas. Prov. de Cautín, IX Región, Chile. Revista Chilena de Antropología 1:61-80.

Gordon, A., J. Madrid y J. Monleón 1972-73. Excavación del cementerio indígena de Gorbea (Sitio GO-3). Provincia de Cautín. Chile. Actas del VI Congreso de Arqueología Chilena / Boletín de Prehistoria Número Especial, pp. 501-522. Universidad de Chile y Sociedad Chilena de Arqueología, Santiago.

Guevara, T. 1929. Historia de Chile: Chile Prehispánico, Tomo II. Universidad de Chile y Establecimientos Gráficos Balcells \& Co., Santiago.

Housse, R. 1940. Epopeya India. Editora Zig-Zag, Santiago.

Inostroza, J. 1985. Pitraco 1: Un Cementerio Tardío en la Araucanía. Boletín del Museo Regional de la Araucanía 2:63-78. Temuco.

Inostroza, J., R. Morris y H. Mora 1986. Descripción de la muestra. En Tesoros de la Araucanía. Colección Raúl Morris von Bennewitz, compilado por J. Inostroza y H. Mora, pp. 14-32. Ilustre Municipalidad de Los Ángeles y Museo Regional de la Araucanía, Los Ángeles y Temuco.

Inostroza, J. y M. Sánchez 1985. Informe preliminar de las excavaciones arqueológicas en el cementerio arqueológicas en el cementerio Pitraco I, comuna de Nueva Imperial, IX Región, Chile. Actas del IX Congreso de Arqueología Chilena, pp. 452461. Museo Arqueológico de La Serena, La Serena.

Inostroza, J. y M. Sánchez 1986. La platería en los sitios arqueológicos. En Tesoros de la Araucanía. Colección Raúl Morris von Bennewitz, compilado por J. Inostroza y H. Mora, pp. 68-77. Ilustre Municipalidad de Los Ángeles y Museo Regional de la Araucanía, Los Ángeles y Temuco.

Joseph, C. 1928. La platería araucana. Anales de la Universidad de Chile, $2^{\mathrm{a}}$ serie, 1er trimestre, pp. 117-158. Santiago.

Mariño de Lobera, P. 1865 [1595]. Crónica del Reino de Chile. Imprenta del Ferrocarril, Santiago.

Menghin, O. 1959-60. Estudios de prehistoria araucana. Acta Praehistorica III-IV:49-120.

Molina, J.I. 1795. Compendio de la Historia Civil del Reyno de Chile, Parte Segunda. Imprenta de Sancha, Madrid.

Morris, R. 1987. Plata de la Araucania: Colección Raul Morris von Bennewitz. SAF, Santiago.

Morris, R. 1997. Los Plateros de La Frontera y la Platería Araucana: en el Proceso Caratulado "Salteo al Cacique Huenul" (1856-1860). Editorial Universidad de La Frontera, Temuco.

Museo Chileno de Arte Precolombino 1983. Catálogo. Platería Araucana, pp. 69-84. Museo Chileno de Arte Precolombino, Santiago.

Núñez de Pineda y Bascuñán, F. 1863 [1673]. Cautiverio Feliz y Razon de las Guerras Dilatadas de Chile. Imprenta del Ferrocarril, Santiago.

Ocaña, D. de 1995 [1600]. "Viaje a Chile”. Relación del Viaje a Chile, año de 1600, Contenida en la Crónica de Viaje Intitulada "A Través de la América del Sur”. Editorial Universitaria, Santiago. 
Ovalle, A. de 1646. Historica Relacion del Reyno de Chile. Francisco Caballo, Roma.

Painecura, J. 2011. Charu: Sociedad y Cosmovisión en la Platería. Consejo Nacional de la Cultura y las Artes y Ediciones Universidad Católica de Temuco, Temuco.

Pérez García, J. 1900 [1810]. Historia Natural, Militar, Civil y Sagrada del Reino de Chile, Tomo I. Imprenta Elzeviriana, Santiago.

Poeppig, E. 1960 [1835]. Un Testigo en la Alborada de Chile (1826-1829). Zig-Zag, Santiago.

Quiroz, D. 2010. Ocupaciones El Vergel en las costas septentrionales de la Araucanía: Una secuencia cronológica por termo-luminiscencia. Actas del XVII Congreso Nacional de Arqueología (Valdivia 2006), Tomo 1, pp. 441-450. Sociedad Chilena de Arqueología, Universidad Austral de Chile y Ediciones Kultrún, Valdivia.

Quiroz, D., M. Sánchez, L. Contreras, F. Constantinescu, R. Campbell, V. Ambos y H. Velásquez 2005. Un sitio habitacional y una sepultura perteneciente al complejo El Vergel en Coronel, Provincia de Concepción. Boletín de la Sociedad Chilena de Arqueología 38:79-91.

Real Academia Española 2001. Diccionario de la Lengua Española, vigésima segunda edición. http://www.rae.es/recursos/ diccionarios/drae (30 de septiembre 2014)

Reccius, W. 1983. Evolución y caracterización de la platería araucana. En Platería Araucana, Catálogo, pp. 17-31. Museo Chileno de Arte Precolombino, Santiago.

Reymond, J. 1971. Cementerio Araucano de Membrillo. Boletín de Prehistoria de Chile 4:87-106.

Rosales, D. de 1877 [1674]. Historia General de el Reyno de Chile. Flandes Indiano, Tomo I. Imprenta del Mercurio, Valparaíso.

Rosales, D. de 1878a [1674]. Historia General de el Reyno de Chile. Flandes Indiano, Tomo II. Imprenta del Mercurio, Valparaíso.

Rosales, D. de 1878b [1674]. Historia General de el Reyno de Chile. Flandes Indiano, Tomo III. Imprenta del Mercurio, Valparaíso.

Ruiz Aldea, P. 1902 [1868]. Los Araucanos i sus Costumbres. Guillermo Miranda, Santiago.

Sánchez, M. 1985. Sepultura de un platero y piezas de platería del cementerio Pitraco 1, Comuna de Nueva Imperial, IX Región. Boletín del Museo Regional de la Araucanía 2:141-145.
Sánchez, M. 1997. El período alfarero en la Isla Mocha. En La isla de las Palabras Rotas, compilado por D. Quiroz y M. Sánchez, pp. 103-131. Biblioteca Nacional de Chile y Centro de Investigaciones Diego Barros Arana, Santiago.

Sánchez, M., J. Inostroza y H. Mora 1985. Investigaciones arqueológicas en los cementerios Deuco 1 y 2, Nueva Imperial, IX Región. Boletín del Museo Regional de la Araucanía 2:146-153.

Schindler, H. 1985. Silver jewelry of the Mapuche. Ornament 8:32-37.

Schindler, H. 1992. Rugendas y los araucanos: apuntes etnográficos. En Rugendas: América de Punta a Cabo. Rugendas y la Araucanía, editado por P. Diener, pp. 71-108. Dirección de Bibliotecas, Archivos y Museos y Goethe Institut, Santiago.

Seguel, Z. 1968. Excavación de salvamento cerca de la localidad de Gomero. Rehue 1:57-62.

Smith, E.R. 1855. The Araucanians: or, Notes of a Tour among the Indian Tribes of Southern Chili. Harper \& Brothers, New York.

Treutler, P. 1958 [1863]. Andanzas de un Alemán en Chile: 1851-1863. Editorial del Pacifico, Santiago.

Urquieta, P. 1978. Anexo 2. Informe sobre piezas dentarias procedentes de Padre Las Casas. En "Urna y canoa funeraria. Una sepultura doble excavada en Padre Las Casas, Provincia de Cautín, IX Región, Chile", publicado por A. Gordon. Revista Chilena de Antropología 1:61-80.

Valdés, C. 1978. Anexo 1. Informe sobre restos óseos humanos del sitio Padre Las Casas, provincia de Cautín, IX Región, Chile. En "Urna y canoa funeraria. Una sepultura doble excavada en Padre Las Casas, Provincia de Cautín, IX Región, Chile", publicado por A. Gordon. Revista Chilena de Antropología 1:61-80.

Valdés, C., M. Sánchez y J. Inostroza 1985. Excavaciones arqueológicas en el cementerio de cistas y canoas Ralipitra 1, Comuna de Nueva Imperial, Prov. de Cautín, IX Región, Chile. Actas del IX Congreso Nacional de Arqueología Chilena, pp. 436-444. Museo Arqueológico de La Serena, La Serena.

Valdés, C., M. Sánchez, J. Inostroza, P. Sanzana y X. Navarro 1985. Excavaciones arqueológicas en el alero Quillén I, Provincia de Cautín, Chile. Actas del IX Congreso Nacional de Arqueología Chilena, pp. 399-435. Museo Arqueológico de La Serena, La Serena.

Vivar, G. de 1979 [1558]. Crónica y Relación Copiosa y Verdadera de los Reinos de Chile. Editado por L. Saéz. Coloqium Verlag, Biblioteca Ibero-Americana Band 27, Berlín.

\section{Notas}

1 Debido a la gran variedad de piezas de la Platería Mapuche, en la Figura 3 solo se han incluido las más representativas. Para más información consultar las referencias señaladas.

2 Sikil: Adorno pectoral ancho formado por una o varias cadenas verticales de tubos o placas articuladas. La o las cadenas son rematadas por una placa redondeada o trapezoidal de la que penden adornos.
3 Trapelakucha: Adorno pectoral angosto formado por una sola cadena vertical de placas articuladas. La cadena es rematada por una cruz de la que pueden pender adornos.

4 Trarilonko: Adorno que rodea la cabeza a nivel frontal. Puede estar formado por una cadena continua de placas o eslabones articulados o bien estar estos adheridos a un soporte flexible como cuero o tela. En ambos casos, puede presentar adornos colgantes. 